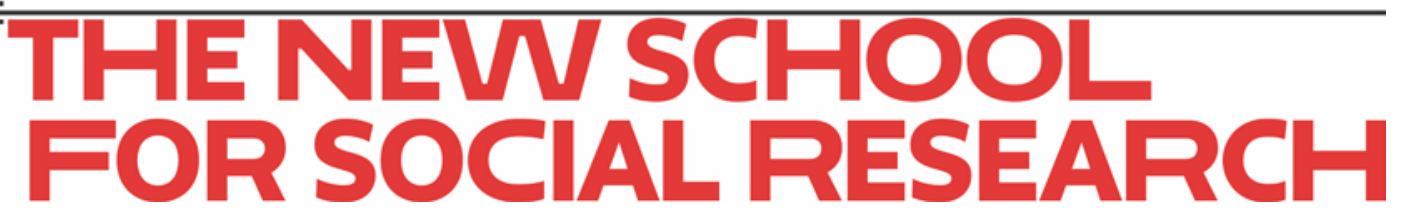

Federico Bassi, Tom Bauermann, Dany Lang, and Mark Setterfield

\title{
Is capacity utilization variable in the long run? An agent-based sectoral approach to modeling hysteresis in the normal rate of capacity utilization
}

June 2020

Working Paper 07/2020

Department of Economics

The New School for Social Research 


\title{
Is capacity utilization variable in the long run? An agent-based sectoral approach to modeling hysteresis in the normal rate of capacity utilization
}

\author{
Federico Bassi, Tom Bauermann, Dany Lang, and Mark Setterfield*
}

August 9, 2021

\begin{abstract}
Post Keynesian macrodynamic models make various assumptions about the normal rate of capacity utilization. Those rooted in the Classical and neo-Keynesian traditions assume the normal rate is fixed, whereas Kaleckian models treat it as a variable that is endogenous to the actual rate of capacity utilization. This paper contributes to the debate about the normal rate of capacity utilization by developing a model of strong or genuine hysteresis, in which firms make discrete decisions about the normal rate depending on the degree of uncertainty about demand conditions. An agent-based model based on empirical analysis of 25 sectors of the US economy is used to show that hysteresis can cause variation in the normal rate of capacity utilization within a subset of the range of observed variation in the actual capacity utilization rate. This suggests that the economy exhibits both constancy and (endogenous) variability in the normal rate of utilization over different ranges of variation in the actual rate. More broadly speaking, the genuine hysteresis model is shown to provide the basis for a synthesis of Post Keynesian macrodynamics that draws on both the Classical/neo-Keynesian and Kaleckian modeling traditions.
\end{abstract}

JEL codes: C63, E11, E12, L6, L7, L9

Keywords: Normal rate of capacity utilization, Harrodian instability, genuine hysteresis, Kaleckian growth theory

*Bassi: Centre de recherche en économie de l'Université Paris Nord (CEPN), Université Sorbonne Paris Nord; email federico.bassi@univ-paris13.fr. Bauermann: Ruhr-University Bochum and Ruhr-Graduate School in Economics; email Tom.Bauermann@ruhr-uni-bochum.de. Lang: Université Sorbonne Paris Nord; email lang.dany@univ-paris13.fr. Setterfield: New School for Social Research; email mark.setterfield@newschool.edu. We gratefully acknowledge that this work was supported by the Ruhr University Research School PLUS, funded by Germany's Excellence Initiative [DFG GSC 98/3]. Federico Bassi also acknowledges the financial support of the AXA Research Fund post-doctoral fellowship program.

An earlier version of this paper was presented at the Meetings of the Eastern Economic Association, Boston, MA February 27 - March 1, 2020. We would like to thank, without implicating, conference participants - and in particular, Ricardo Summa - for their helpful comments. 


\section{Introduction}

Assumptions about the normal rate of capacity utilization are crucial in Post Keynesian macrodynamic models. The debate revolves around two positions, Kaleckian and Classical/ neoKeynesian. For Classical/neo-Keynesian economists (Serrano, 1995; Skott, 2010), the normal rate of capacity utilization is fixed and the actual rate adjusts towards the normal rate in the long run. Kaleckian authors such as Lavoie (1996) and Dutt (1997) instead emphasize that the normal rate is a variable that adjusts to the actual rate of capacity utilization. Skott (2012) criticizes the Kaleckian approach on the grounds that it lacks: 1) proper behavioral foundations; 2) an explanation as to why the normal rate of capacity utilization should be treated as a conventional variable; and 3) justification for a process of adaptation in the normal rate that is both quantitatively fast and unbounded $!^{1}$ Setterfield and Avritzer (2019) take up these points by suggesting a genuine hysteresis mechanism operating in the normal rate of capacity utilization. They argue that the normal rate depends on fluctuations in the actual rate of capacity utilization because the latter reflects variations in uncertainty about aggregate demand and that, in the absence of rational expectations, the normal rate of capacity utilization must be partly conventional because it reflects rational behavior under uncertainty. Finally, it is claimed that the genuine hysteresis model provides a basis for countering the third critique of Skott (2012).

The analysis in Setterfield and Avritzer (2019) is, however, lacking in several respects. First, the authors analyze hysteresis on a purely macroeconomic, i.e. aggregate, level. Capitalist economies are diversified, however, made up of different industries (sectors) with potentially different properties and, in particular, different normal rates of capacity utilization $\sqrt{2}^{2}$ The approach taken in this paper therefore involves analyzing the normal rate of capacity utilization at the industry level.

\footnotetext{
${ }^{1}$ Similar criticisms can be found in Nikiforos $(2016)$, despite the author's finding that the normal rate of utilization is, in fact, endogenous to the actual rate at both micro and macro levels.

${ }^{2}$ On the potential importance of heterogeneity at the sectoral level for Kaleckian macroeconomics, see also Fujita 2019).
} 
Second, even within specific sectors, decisions about the normal rate of capacity utilization are made by individual firms. With the exception of Nikiforos 2013, 2016), this has not been considered properly (to date) in the literature on hysteresis in the normal rate. We therefore develop an agent-based model (ABM) that ultimately roots the mechanisms of genuine hysteresis in firm-level decisions. The approach taken is similar to the application of agent-based models in (social) sciences elsewhere (Railsback and Grimm, 2011). Third, the paper combines micro- and mesoeconomic modeling with macroeconomics by drawing out the implications of genuine hysteresis at the sectoral level for traditional one-sector, aggregate structural Post Keynesian macrodynamic models. These implications include a modified Kaleckian treatment of the normal rate of capacity utilization that serves to combine Classical/neo-Keynesian and Kaleckian adjustment dynamics. Indeed, our model suggests that there are periods of stability of the normal rate of capacity utilization when the actual rate revolves around the normal rate, without any feedback effects from the actual to the normal rate. But there are also periods of instability in the normal rate of capacity utilization that are driven by the volatility of the actual rate of capacity utilization, such that the (unstable) dynamics of the actual rate determine the (unstable) dynamics of the normal rate. In other words, there is a reciprocal influence as between the actual and normal rates of capacity utilization.

The remainder of the paper is organized as follows. Section 2 provides a brief overview of the genuine hysteresis approach to modeling variation in the normal rate of capacity utilization. Genuine hysteresis is shown to be an aggregate property of systems characterized, at the micro level, by a multiplicity of heterogeneous, non-linear and discontinuous responses to input variations that produce, at the macro level, non-linear and discontinuous (although smoother) output variations. In section 3, we provide empirical evidence of a negative, nonlinear and discontinuous relationship between volatility and long run variation of the rate of capacity utilization: periods of high volatility correspond to periods of low utilization, while periods of low volatility correspond to periods of high utilization. In particular, we insist on 
the non-linearity and discontinuity of this relationship, which makes the concept of genuine hysteresis appropriate for modeling this relationship. Section 4 then builds a simple agentbased model with genuine hysteresis, whereby the input variable is the volatility of the rate of utilization and the output variable is the normal rate of utilization at firm level. This model, after appropriate calibration, allows us to explain and reproduce the negative non-linear and discontinuous relationship between volatility and long-run variation of the rate of capacity utilization, at both the sectoral and the aggregate levels. In section 5, we present the implications of the statistical and computational analyses in sections 3 and 4 for Post Keynesian macroeconomic modeling. Specifically, we show that our agent-based model provides a micro-founded justification for certain aggregate models of hysteresis in the normal rate of capacity utilization, based on a two-way interaction between the actual and normal rates of capacity utilization. Finally, section 6 ends with a brief summary of the main results and findings of the paper, and its implications for future research and policy.

\section{Theoretical background and motivation}

The past four decades have witnessed repeated appeals to the concept of hysteresis in macroeconomics, in a by-now large literature that is often associated with critiques of the concept of a natural rate of unemployment (and the related claim that the Phillips curve is vertical - i.e., that there is no trade-off between inflation and real activity in the long run) ${ }^{3}$ A signal feature of hysteresis - and one that explains its attraction in the literature just noted - is that transitory causes (shocks) can have permanent effects. Hence even if one begins with the canonical (neoclassical) concepts of a natural rate of unemployment and vertical long-run Phillips curve as a starting point, if transitory shocks can cause departures from the natural rate of unemployment, and if such departures change the value of the natural rate itself, then the economy will

\footnotetext{
${ }^{3}$ The genesis of this 'hysteresis in the natural rate of unemployment' literature is often associated with Blanchard and Summers (1986), though see Hargreaves Heap (1980).
} 
eventually settle at an equilibrium consistent with a new (higher or lower) long-run rate of unemployment. This means that the long run Phillips curve cannot be vertical $]^{4}$ It also overturns the Friedmanite policy implications of the original natural rate hypothesis, according to which monetary policy interventions that lower unemployment in the short run can only have inflationary consequences in the long run, by virtue of the fixity of the natural rate. With hysteresis, such policy interventions (and, indeed, most nominal 'shocks') are revealed to affect the real economy in the long run. The so-called natural rate of unemployment remains an integral feature of the analysis, although how 'natural' it can be considered if the value varies in response to the actual rate of unemployment is, of course, debatable (Solow, 1986, p.S33) $!^{5}$

Unfortunately, however, appeal to hysteresis in economic theory is often done badly, ${ }^{6}$ at least according to those familiar with the origins and development of the concept in the physical sciences (Amable et al., 1993, 1994; Cross, 1993b; Bassi and Lang, 2016). For instance, the term 'hysteresis' is often (indeed, usually) used as a synonym for path dependence, when it is, in fact, a particular form of path dependence with specific properties that are not shared with other forms of path dependence - such as lock in and cumulative causation, for example (Setterfield, 2009). Moreover, the formal structure of hysteresis is frequently (mis)represented as arising from the presence of a unit (zero) root in systems of linear difference (differential) equations (Amable et al. 1993, 1994, Cross, 1993b). This gives rise to two problems. First, the continuity implicit in linear difference (differential) equations overlooks the fact that hysteresis is, in fact, associated with discontinuities in the adjustment dynamics of a system. Second, it altogether misrepresents the fundamental nature of hysteresis. In terms of the conventional 'triad' of equilibrium analysis (existence, uniqueness, and stability), unit/zero root systems give

\footnotetext{
${ }^{4}$ In fact, if the short run change in inflation associated with the transitory shock to unemployment is modest, the process described above will produce a long run Phillips curve that is essentially horizontal - consistent with empirical work showing that an important part of the Phillips curve is, in fact, flat (Eisner 1997).

${ }^{5}$ In particular, a hysteretic 'natural' rate of unemployment is not determined exclusively on the supply-side of the economy, but is, instead, influenced by variations in aggregate demand.

${ }^{6}$ As a consequence, the same could be said of the empirical literature in macroeconomics that claims to test for the presence or absence of hysteresis effects.
} 
rise to a continuum of equilibria and thus undermine the property of uniqueness. Hysteresis, however, undermines the classical mechanical stability properties of equilibrium. In a hysteretic system, there may very well be a unique equilibrium at any point in time. Nevertheless, the system need not revert to its initial equilibrium position following displacement from this position, but will instead settle into a new equilibrium position that is a product of the disequilibrium adjustment it has just experienced, and that would not have existed as an equilibrium position in the absence of this historical experience. These and other properties of hysteresis are properly captured by the analytical model of 'genuine' hysteresis developed in the physical sciences and introduced to economics by authors such as Amable et al. (1993, 1994) and Cross (1993b). All this having been said, however, some authors recommend a 'hybrid' or pragmatic position on the modeling of hysteresis, according to which unit or zero root systems are used as a first approximation even as it is recognized that such systems do not give rise to proper hysteresis (Setterfield, 2009) 7

A proclivity to appeal to the concept of hysteresis has made its way into the debate concerning the long run behavior of the rate of capacity utilization in heterodox macrodynamics, particularly among Kaleckian authors (Lavoie, 1995, 1996, 2010, Dutt, 1997, 2009, 2010) 8 The normal rate of capacity utilization is very different from the so-called natural rate of unemployment. While the latter is usually associated with market-clearing outcomes in the labor market consistent with correct expectations, the former is widely considered to be a convention designed to cope with fundamental uncertainty about demand in the goods market.$^{9}$ The

\footnotetext{
${ }^{7}$ This 'hybrid' or pragmatic position can be associated with the methodological position on the complexity of macroeconomic models associated with Krugman (2000). As will become clear, it provides a basis for some of the lessons for modeling hysteresis in the normal rate of capacity utilization that can be drawn from the analysis in this paper.

${ }^{8}$ Earlier intimations of this thinking can be found in Amadeo (1987) and even as far back as Robinson (1956. pp.186-90).

${ }^{9}$ Conceptions of the normal rate of capacity utilization do differ, however. For example, Kurz (1986 1990) derives the normal rate from cost-minimizing behaviour associated with the optimal choice of technique by firms. See, for example, Trezzini and Pignalosa (2021) on the historical development of the concept of a normal rate of capacity utilization.
} 
essential argument in the Kaleckian literature is that, whereas Classical and neo-Keynesian authors are inclined to regard the normal rate of capacity utilization as a fixed point towards which the actual rate of capacity utilization must converge ${ }^{10}$ the normal rate should be thought of instead as endogenous to the actual rate. This thinking is potentially consistent with hysteresis: in principle, even a strictly temporary shock that separates the actual from the normal rate of capacity utilization could move the latter towards the former so that, by the time the actual and normal rates equalize (and the economy achieves a 'fully-adjusted' position), the normal rate of capacity utilization, and hence the long run rate of capacity utilization, has changed.11

Unfortunately, all this is achieved without modeling variation in the normal rate of capacity utilization in a manner consistent with genuine hysteresis. Instead, Kaleckians postulate two possible closures in macrodynamic models that involve the normal rate of capacity utilization:

$$
u_{n}=\bar{u}_{n}
$$

and:

$$
\dot{u}_{n}=\beta\left(u-u_{n}\right)
$$

Equation (1) can be termed the Classical/neo-Keynesian closure, and treats the normal rate of capacity utilization as exogenously given. In the event of short-term variation in the actual capacity utilization rate, a fully-adjusted position can only be restored by reversion of the actual rate towards its (fixed) normal rate. Equation (2), meanwhile, is the Kaleckian closure. This makes the normal rate of capacity utilization endogenous to the actual rate so that if, for example, the actual rate rises above the normal rate $\left(u>u_{n}\right)$, the normal rate increases and a fully-

\footnotetext{
${ }^{10}$ Strictly speaking, it is treated as a structural variable determined independently of variation in the actual rate of utilization.

${ }^{11}$ Note the correspondence in the example just described between the outcome of these dynamics - a permanent change in the equilibrium capacity utilization rate resulting from a temporary change in the actual utilization rate - and the signal feature of hysteresis (permanent change as a result of transitory cause) highlighted earlier in this discussion.
} 
adjusted position is restored at a new, higher, normal rate of capacity utilization. The Kaleckian closure in (2) is thus associated with hysteresis. However, the formal structure of equation (2) means that it can be associated with the unit/zero root approach to modeling hysteresis that was criticized earlier. To see this, first note that it follows from (2) that:

$$
\dot{u}_{n} \approx u_{n t}-u_{n t-1}=\beta\left(u_{t}-u_{n t-1}\right)
$$

Now assume that:

$$
u_{t}=u_{n t-1}+\varepsilon_{t} \quad, \quad \varepsilon \sim\left(0, \sigma_{\varepsilon}^{2}\right)
$$

Substituting this last expression into (3), we get:

$$
u_{n t}=u_{n t-1}+\beta \varepsilon_{t}
$$

The expression in equation (4) is a unit root process $\left(\frac{d u_{n t}}{d u_{n t-1}}=1\right)$. Assume that $u_{n t}=u_{n t-1}=u_{n 1}$ initially. Now assume that in some period $i, \varepsilon_{i}=\alpha \neq 0$ while $\varepsilon_{t}=0 \quad \forall \quad t>i$. Then by equation (4) we will observe:

$$
\begin{gathered}
u_{n i}=u_{n i-1}+\beta \varepsilon_{i}=u_{n 1}+\beta \alpha \\
\Rightarrow u_{n i}=u_{n 2}
\end{gathered}
$$

and:

$$
u_{n t}=u_{n 2} \quad \forall \quad t>i
$$

The unit root in the difference equation with which we began ensures that the system does not revert to $u_{n 1}$ despite the strictly transitory nature of the disturbance to which it was subject, but instead permanently bears the mark of the temporary event $\varepsilon_{i} \neq 0,12$

More recently, Setterfield and Avritzer (2019) have outlined a Kaleckian model in which vari-

\footnotetext{
${ }^{12}$ Difference equations with non-zero roots will, in the event of transitory shock, revert towards or diverge further
} 
ation in the normal rate of capacity utilization is associated with genuine hysteresis. In this model, firms maintain a normal rate of capacity utilization below one to insulate themselves from variations in product demand that are unforeseen (due to fundamental uncertainty) and that, were they to result in foregone opportunities for expansion, would result in loss of market share and hence loss of power over the external (market) environment. But it is a stylized fact that the volatility of the goods market is subject to discrete variations, lower volatility prevailing during the long periods of growth and tranquility associated with long-wave booms (such as the post-war Golden Age), and higher volatility arising during the shorter periods of crisis that end these long booms. According to Setterfield and Avritzer (2019), this will induce firms to maintain two normal rates of capacity utilization, suited to the two different volatility environments they periodically encounter, and to engage in discrete switching between the 'high' and 'low' values of the normal rate of capacity utilization they maintain as they perceive the economy to be enmeshed in regimes of either low or high product market volatility (respectively).

This theory lends itself to representation in terms of the analytical apparatus of genuine hysteresis. To see this, consider first figure 1, In figure 1, we depict a non-ideal relay illustrating the workings of genuine hysteresis in the normal rate of capacity utilization at firm-level. The upper and lower 'arms' of the non-ideal relay correspond to $u_{n H}$ and $u_{n L}$, the upper and lower values of the normal rate of capacity utilization. $c_{\sigma L}$ and $c_{\sigma H}$, meanwhile, are the critical values of $\sigma_{u}$, the volatility of the aggregate economy or market environment in which the firm operates, that induce switching between $u_{n H}$ and $u_{n L}$ as the firm seeks to operate at a normal rate away from any fixed point at which they begin. Consider, for example, the system:

$$
x_{t}=\delta+\gamma x_{t-1}+\varepsilon_{t} \quad, \quad \gamma<0
$$

where, once again, $\varepsilon \sim\left(0, \sigma_{\varepsilon}^{2}\right)$ and with $x=x_{0}$ and $\varepsilon_{0} \neq 0$ (and $\varepsilon_{t}=0 \quad \forall \quad t>0$ ) in some initial period zero. It follows that:

$$
\begin{gathered}
x_{t}=\left(1+\gamma+\ldots+\gamma^{t}\right) \delta+\gamma^{t-1}\left(\gamma x_{0}+\varepsilon_{0}\right) \\
\Rightarrow \lim _{t \rightarrow \infty} x_{t}=\frac{\delta}{(1-\gamma)}
\end{gathered}
$$

This is a standard 'reversion towards a fixed point' result characteristic of most equilibrium models in economics. 
of capacity utilization that insulates it sufficiently from unforeseen future variations in product demand. Starting with the firm operating with $u_{n}=u_{n H}$ at point $A$, a sustained increase in the volatility of the actual rate of capacity utilization of size $e_{1}$ induces the firm to reduce its normal rate of capacity utilization from $u_{n H}$ to $u_{n L}$ as a hedge against large unforeseen increases in future product demand. The firm thus settles at point $B$ in figure 1 . However, if there is now a reduction in volatility of identical magnitude to the previous increase $\left(e_{2}=e_{1}\right)$, thus restoring the level of volatility to the status quo ante, the firm wil not revert to $u_{n H}$ because volatility has not fallen below the critical value $c_{\sigma L}$ (the threshold value that signals a 'significant' reduction in $\sigma_{u}$ meritorious of behavioral change, bearing in mind the essential motivation for maintaining $\left.u_{n}<1\right)$. Instead, the firm settles at point $C_{1}$. Only if the reduction in volatility is sufficiently large enough to reduce $\sigma_{u}$ below $c_{\sigma L}-$ such as the reduction of size $e_{3}$ depicted in figure $1-$ will the firm increase $u_{n}$ from $u_{n L}$ to $u_{n H}$ (bringing it to point $C_{2}$ ). In this way, discrete variations in $u_{n}$ occur in response to sufficiently large variations in the volatility of the firm's environment, and as demonstrated by the the movement from $A$ to $B$ to $C_{1}$ in figure 1 , even transitory variations in volatility can have lasting (indeed, ceteris paribus, permanent) effects on $u_{n}$.

The model developed in Setterfield and Avritzer (2019) is a single-sector, aggregate structural model, so figure 1 is conceived as depicting the behavior of a single, representative firm. In this case, the aggregate normal rate of capacity utilization can only vary discretely between the two extreme values $u_{n L}$ and $u_{n H}$ in figure 1. Genuine hysteresis in aggregate outcomes is, however, properly conceived as arising from microfoundations that rest on heterogeneous parts. In other words, genuine hysteresis in the aggregate normal rate of capacity utilization would arise from aggregation of the behavioural responses of multiple firms, with differing values of $u_{n L}, u_{n H}$ and/or $c_{\sigma_{L}}$ and $c_{\sigma_{H}}$, responding (in accordance with the principles illustrated in figure 1 and outlined above) to variations in the volatility of the economy. Ultimately, such variation can be (more or less) continuous even as variation in the normal rate at firm-level is discrete, due to heterogeneity in the micro-structure of the economy. In this way, genuine hysteresis in 
Figure 1: Modeling genuine hysteresis in capacity utilization

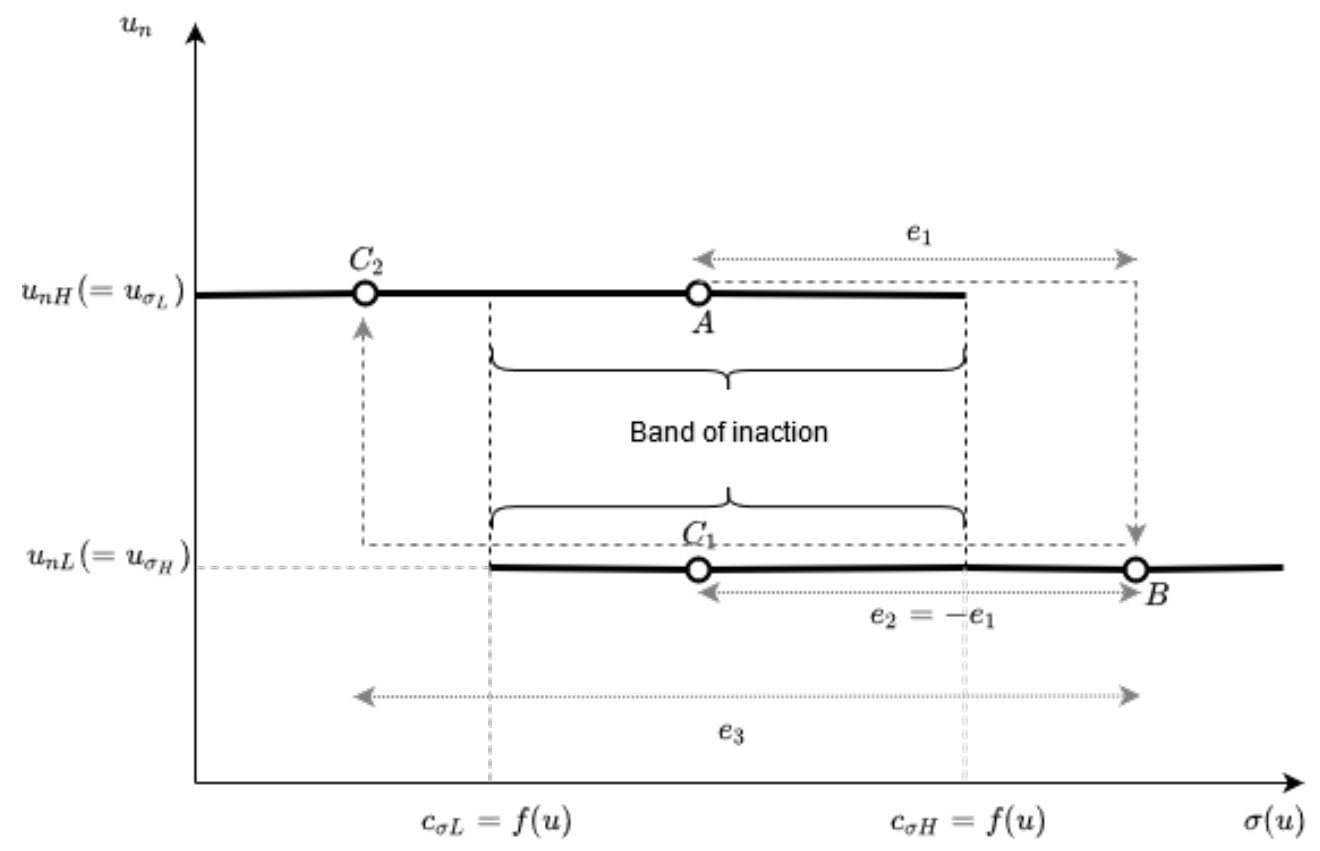

the normal rate of capacity utilization can be associated with compositional change (change in the proportion of firms operating at either $u_{n L}$ to $u_{n H}$ ) in an economy characterized by heterogeneity among firms. The immediate purpose of what follows is to demonstrate these claims more concretely, by constructing a microfounded genuine hysteretic model of variation in the normal rate of capacity utilization at the sectoral level. 


\section{Empirical analysis of volatility and the normal rate of capac- ity utilization}

\subsection{Empirical analysis of hysteresis effects}

Based on Steindl (1952), uncertainty about demand conditions is a basic motivation for firms to plan to operate with excess capacity (i.e., to set $u_{n}<1$ ). It follows that an increase in uncertainty can induce a lower value of $u_{n}$ to accommodate bigger potential future variations in demand and, hence, realized capacity utilization rates. Therefore, and assuming backward-looking behavior on the part of firms, larger fluctuations in the actual rate of capacity utilization in the past indicate times of rising uncertainty for firms. Setterfield and Avritzer (2019) show that there is a negative relation between the volatility in the actual rate of capacity utilization and the normal rate of capacity utilization in the aggregate. Nevertheless, the authors do not address whether or not such a relationship exists at the micro- and mesoeconomic levels.

The empirical analysis in this paper has two objectives. First, it tests whether the inverse relationship between uncertainty and the normal capacity utilization rate reported by Setterfield and Avritzer (2019) exists at the mesoeconomic level, i.e., for 25 manufacturing sectors of the US economy ${ }^{13}$ Second, and with reference to figure 1, we seek evidence for the basic properties of genuine hysteresis in the normal rate of capacity utilization at the sectoral level. The sectors are the same as in Setterfield (2019) and the data were taken from the Federal Reserve Data (FRED) on the capacity utilization rate ${ }^{14}$ We take monthly data on the actual capacity

\footnotetext{
${ }^{13}$ The non-constancy of the volatility of the economy, and the inverse relationship between volatility and the actual rate of capacity utilization as between long booms (sustained periods of high capacity utilization) and short crises (characterized by low capacity utilization) are assumed to be characteristics of the mesoeconomic level as they are, in Setterfield and Avritzer (2019), of the economy as a whole.

${ }^{14}$ These sectors are: Apparel and leather goods; Chemical; Computers and electronic product; Computers, communications equipment, and semiconductors; Crude processing; Electrical equipment, appliance, and component; Electric power generation, transmission, and distribution; Fabricated metal product; Food, beverage, and tobacco; Furniture and related products; Machinery; Mining; Miscellaneous; Motor vehicles and parts; Natural gas distribution; Non-metallic mineral mining and quarrying; Oil and gas extraction; Paper; Petroleum and coal products; Plastics and rubber products; Primary metal; Printing and related support activities; Textiles and prod-
} 
utilization rate from 1972 to 2018 and split the data into 47 years. For each year, we compute the average actual capacity utilization rate and its standard deviation. Taking into consideration the critique of Botte (2019), we then compute the normal rate of capacity utilization $\left(u_{n}\right)$ as the five-year moving average (5-MA) of the average capacity utilization rates calculated for each calendar year and removed the linear trend ${ }^{15}$ We also compute a five-year moving average (5-MA) of the standard deviation calculated for each calendar year. The (filtered) standard deviation indicates the volatility of the actual rate of capacity utilization $\left(\sigma_{t}\right)$, and provides a measure of the uncertainty faced by firms (as in Setterfield and Avritzer (2019) and Jurado et al. (2015)).

In their paper on the effect of real sales on hysteretic employment, Mota et al. (2012) present three criteria that indicate hysteresis. We refer to Mota et al. (2012) for our first econometric tests. The data can be said to confirm the predictions of the non-ideal relay (figure 1 ) in our model if the following conditions are met:

i) As depicted in figure 1 , when $\sigma_{t-1}$ increases we should see that the normal rate of capacity utilization decreases. In other words, we should see a negative correlation between changes in $\sigma_{t-1}$ and changes in $u_{n}$.

ii) Further shown by the non-ideal relay (figure 1), firms do not constantly adjust $u_{n}$ as $\sigma$ changes, but instead change $u_{n}$ only when $\sigma$ exceeds or falls below certain critical values. Therefore, given changes in $\sigma$, one should see that the frequency of non-adjustment in $u_{n}$ should dominate positive and negative changes in $\sigma$ over the sample period from 1972 to 2018.

iii) Finally, and in line with (ii), we should see an asymmetry in the impulses from $\sigma_{t-1}$ and the responses from $u_{n}$ - specifically, we should see that the variation of $\sigma_{t-1}$ exceeds the variation of $u_{n}$.

Table 1 shows the results with respect to the above-mentioned criteria. The last column of ucts; Transportation equipment; Wood product

${ }^{15}$ We varied the lags for the MA-filter from 3 to 7 . The results remained nearly unaffected. 
the table 1 and figures 11 to 13 in the Appendix show that the correlation between $\Delta \sigma$ and $\Delta u_{n}$ is negative for nearly all sectors. Criterion (i) is mainly confirmed, although the observed correlation is very low in the sectors Electric power generation, transmission and distribution, Food, beverage and tobacco, Natural gas distribution and Oil and gas extraction. Columns 2 to 5 of table 1 show the magnitude of the adjustments in $u_{n}$, given changes in $\sigma_{t-1}$. As is can be seen in the mentioned columns, for the majority of the sectors $u_{n}$ does not significantly change when $\sigma_{t-1}$ changes. These columns therefore confirm the prediction of the non-ideal relay (criterion (ii)). The frequency of non-adjustment dominates the positive and negative spikes for the period from 1972 to 2018 in most of the sectors. Further, columns 4 and 5 show the variation in the rates of changes in $\sigma_{t-1}$ exceed the variation in $\Delta u_{n}$, which indicates that firms are reluctant to change $u_{n}$ in response to any and every change in $\sigma_{t-1}$. Hence, criterion (iii) is also confirmed. 
Table 1: Frequency of (non-)adjustment to changes in the volatility of actual capacity utilization

\begin{tabular}{|c|c|c|c|c|c|c|}
\hline Sector & $\begin{array}{l}\text { frequency } \\
\text { of positive } \\
\text { spikes }\end{array}$ & $\begin{array}{l}\text { frequency } \\
\text { of negative } \\
\text { spikes }\end{array}$ & $\begin{array}{l}\text { frequency } \\
\text { of non- } \\
\text { adjust. }\end{array}$ & $\begin{array}{l}\text { Variation } \\
\text { in } \Delta u_{n}\end{array}$ & $\begin{array}{l}\text { Variation } \\
\text { in } \Delta \sigma\end{array}$ & $\begin{array}{l}\text { Cor. } \Delta u_{n} \\
\text { and } \Delta \sigma_{t-1}\end{array}$ \\
\hline Apparel and leather goods & 0.07 & 0.26 & 0.67 & 0.014 & 0.212 & -0.491 \\
\hline Chemical & 0.13 & 0.20 & 0.67 & 0.015 & 0.221 & -0.355 \\
\hline Computer and electronic product & 0.13 & 0.26 & 0.61 & 0.021 & 0.225 & -0.338 \\
\hline $\begin{array}{l}\text { Computers, communications } \\
\text { equipment and semiconductors }\end{array}$ & 0.17 & 0.28 & 0.54 & 0.027 & 0.245 & -0.328 \\
\hline Crude processing & 0.04 & 0.13 & 0.83 & 0.011 & 0.232 & -0.313 \\
\hline $\begin{array}{l}\text { Electric power generation, } \\
\text { transmission and distribution }\end{array}$ & 0.07 & 0.20 & 0.74 & 0.011 & 0.232 & -0.168 \\
\hline $\begin{array}{l}\text { Electrical equipment appliance } \\
\text { and component }\end{array}$ & 0.20 & 0.33 & 0.48 & 0.012 & 0.133 & -0.587 \\
\hline Fabricated metal product & 0.22 & 0.28 & 0.50 & 0.021 & 0.254 & -0.492 \\
\hline Food, beverage and tobacco & 0.00 & 0.07 & 0.93 & 0.007 & 0.161 & -0.121 \\
\hline Furniture and related products & 0.22 & 0.33 & 0.46 & 0.027 & 0.182 & -0.365 \\
\hline Machinery & 0.28 & 0.33 & 0.39 & 0.028 & 0.181 & -0.519 \\
\hline Mining & 0.07 & 0.11 & 0.83 & 0.011 & 0.222 & -0.213 \\
\hline Miscellaneous & 0.37 & 0.24 & 0.39 & 0.012 & 0.128 & -0.363 \\
\hline Motor vehicles and parts & 0.30 & 0.33 & 0.37 & 0.044 & 0.182 & -0.575 \\
\hline Natural gas distribution & 0.07 & 0.17 & 0.76 & 0.013 & 0.085 & -0.004 \\
\hline $\begin{array}{l}\text { Non-metallic mineral mining } \\
\text { and quarrying }\end{array}$ & 0.17 & 0.15 & 0.67 & 0.022 & 0.127 & -0.385 \\
\hline Oil and gas extraction & 0.00 & 0.00 & 1.00 & 0.007 & 0.219 & -0.143 \\
\hline Paper & 0.07 & 0.02 & 0.91 & 0.010 & 0.202 & -0.679 \\
\hline Petroleum and coal products & 0.11 & 0.22 & 0.67 & 0.017 & 0.145 & -0.39 \\
\hline Plastics and rubber products & 0.28 & 0.33 & 0.39 & 0.025 & 0.178 & -0.425 \\
\hline Primary metal & 0.22 & 0.35 & 0.43 & 0.032 & 0.157 & -0.392 \\
\hline $\begin{array}{l}\text { Printing and related } \\
\text { support activities }\end{array}$ & 0.13 & 0.26 & 0.61 & 0.018 & 0.174 & -0.336 \\
\hline Textiles and products & 0.11 & 0.28 & 0.61 & 0.021 & 0.255 & -0.564 \\
\hline Transportation equipment & 0.22 & 0.24 & 0.54 & 0.024 & 0.210 & -0.489 \\
\hline Wood product & 0.24 & 0.33 & 0.43 & 0.032 & 0.222 & -0.574 \\
\hline Total Industy & 0.09 & 0.17 & 0.74 & 0.013 & 0.262 & -0.61 \\
\hline
\end{tabular}

Source: Federal Reserve Bank of St. Louis (FRED) and the US, and own calculation.

Description: The first column shows the industries, following the classification of the US industries by FRED Setterfield 2019]. The column 2 to 4 show the frequency of various magnitudes of period-to-period-changes in $u_{n}$, i.e. frequency of positive spikes $\left(\frac{\Delta u_{n}}{u_{n}}>1.5 \%\right)$, frequency of negative spikes $\left(\frac{\Delta u_{n}}{u_{n}}<-1.5 \%\right)$ and inaction $\left(\frac{\Delta u_{n}}{u_{n}}<|1.5 \%|\right)$. They are expressed as the share of all changes. Columns 5 and 6 show the standard deviation of the period-toperiod-changes in $u_{n}$ and $\sigma_{t-1}$. 


\subsection{Estimation of the sectoral threshold values of $u_{n}$ and $c_{\sigma}$}

This section presents further evidence for the genuine hysteresis model (figure 1), seeking in the process to approximate $u_{n H}$ and $u_{n L}$ and establish threshold values for $\sigma_{t-1}$ on the sectoral level. A common approach to empirically analyzing the hysteresis mechanism depicted in figure 1 involves estimating a discrete threshold regression model (Hansen, 1999) for all 25 sectors (e.g. Belke et al. (2015)). The discrete threshold regression model, which we apply to approximate the sector-specific values of $u_{n L}$ and $u_{n H}$, estimates two linear regressions with two different intercepts plus an error term. The regressions are separated by the threshold value of $\sigma_{t-1}$. In other words, we estimate the sector-specific values of $u_{n H}$ and $u_{n L}$ as two constants with error terms, as follows:

$$
\begin{aligned}
& u_{n t}=C_{1}+\epsilon_{t} \quad \text { if } \quad 0<\sigma_{t-1}<\sigma_{\text {thresh }} \\
& u_{n t}=C_{2}+\epsilon_{t} \quad \text { if } \quad \sigma_{\text {thresh }}<\sigma_{t-1}<\infty
\end{aligned}
$$

In equations (20) and (21), the normal capacity utilization rate is the dependent variable and $\sigma_{t-1}$ is the threshold variable, with $C_{2}<C_{1}$ if our postulated inverse relationship between volatility and the normal rate of capacity utilization is valid. As previously noted, we use a detrended five-year moving average (5-MA) of the annual rate of capacity utilization as a proxy for the aggregate normal rate of capacity utilization, while the volatility variable $\sigma_{t-1}$ is the five-year moving average (5-MA) of the standard deviation of the actual rate of capacity utilization within each calendar year. In table 2 , we see that in most sectors, whenever the volatility switches from below to above a certain threshold value (and vice versa), the normal rate of capacity utilization switches from a high utilization regime, $u_{n H}$, to a low utilization regime, $u_{n L}$ (and vice versa). The second and third columns of table 2 report the estimated intercept values according to the volatility regime $\left(u_{n L}\right.$ and $u_{n H}$ respectively), while the fourth column reports the estimated threshold value of volatility. In addition, figures 14 to 16 in the Appendix show the negative 
and non-linear relationship between volatility and the normal rate of capacity utilization derived from our threshold regression model. This is an additional confirmation of the hysteresis mechanism at the mesoeconomic level and the previous works of Setterfield (2019) and Setterfield and Avritzer (2019). Table 10 in the Appendix provides a robustness check for our results.

Table 2: Results: discrete threshold regression model

\begin{tabular}{|c|c|c|c|c|}
\hline Sector & $C_{1}$ & $C_{2}$ & Threshold $\sigma_{t-1}$ & $R^{2}$ \\
\hline Apparel and leather goods & $80.84^{* * *}$ & $75.72^{* * *}$ & 1.23 & 0.376 \\
\hline Chemical & $78.54^{* * *}$ & $75.05^{* * *}$ & 1.24 & 0.396 \\
\hline Computer and electronic product & $79.18^{* * *}$ & $73.08^{* * *}$ & 2.01 & 0.696 \\
\hline Computers, communications equipment, and semiconductors & $78.61^{* * *}$ & $72.85^{* * *}$ & 2.57 & 0.313 \\
\hline Crude processing & $86.90^{* * *}$ & $84.74^{* * *}$ & 1.65 & 0.309 \\
\hline Electrical equipment, appliance, and component & $84.69^{* * *}$ & $80.85^{* * *}$ & 1.45 & 0.230 \\
\hline Electric power generation, transmission and distribution & $87.01^{* * *}$ & - & - & - \\
\hline Fabricated metal product & $78.33^{* * *}$ & $73.58^{* * *}$ & 2.16 & 0.149 \\
\hline Food, beverage and tobacco & $80.76^{* * *}$ & - & - & - \\
\hline Furniture and related products & $78.88^{* * *}$ & $75.36^{* * *}$ & 1.59 & 0.157 \\
\hline Machinery & $79.17^{* * *}$ & $72.20^{* * *}$ & 2.66 & 0.286 \\
\hline Mining & $88.37^{* * *}$ & $85.90^{* * *}$ & 1.53 & 0.230 \\
\hline Miscellaneous & $77.58^{* * *}$ & $75.25^{* * *}$ & 1.12 & 0.374 \\
\hline Motor vehicles and parts & $78.62^{* * *}$ & $69.15^{* * *}$ & 4.31 & 0.477 \\
\hline Natural gas distribution & $80.47^{* * *}$ & - & - & - \\
\hline Non-metallic mineral product & $84.73^{* * *}$ & $77.51^{* * *}$ & 3.13 & 0.692 \\
\hline Oil and gas extraction & $92.81^{* * *}$ & - & - & - \\
\hline Paper & $88.10^{* * *}$ & $86.08^{* * *}$ & 1.23 & 0.292 \\
\hline Petroleum and coal products & $87.15^{* * *}$ & $80.91^{* * *}$ & 1.87 & 0.319 \\
\hline Plastics and rubber products & $85.18^{* * *}$ & $79.33^{* * *}$ & 1.36 & 0.422 \\
\hline Primary metal & $81.26^{* * *}$ & $74.55^{* * *}$ & 3.52 & 0.237 \\
\hline Printing and related support activities & $81.57^{* * *}$ & $77.20^{* * *}$ & 1.30 & 0.258 \\
\hline Textiles and products & $81.16^{* * *}$ & $76.27^{* * *}$ & 1.82 & 0.261 \\
\hline Transportation equipment & $75.99^{* * *}$ & $68.41^{* * *}$ & 3.30 & 0.569 \\
\hline Wood product & $80.16^{* * *}$ & $71.55^{* * *}$ & 2.18 & 0.692 \\
\hline
\end{tabular}

Source: Federal Reserve Bank of St. Louis (FRED) and the US, and own calculations.

Notes: ${ }^{* * *}$ denotes significance at the $0.1 \%$ level.

Description: The Table shows the results for a threshold regression model, estimated via OLS. The data was trimmed by $15 \%$ for the regression. The normal rate of capacity utilization $\left(u_{n}\right)$ is the dependent variable. The threshold is tested via the Bai-Perron test (Bai and Perron, 2003). The model tests whether a threshold value of $\sigma_{t-1}$ exists such that the OLS regression yields two constants $\left(C_{1}\right.$ and $\left.C_{2}\right)$ for $u_{n}$. For most of the sectors, intercept $C_{1}$ is above intercept $C_{2}$, which implies that the normal rate of capacity utilization is higher in case of $\sigma_{t-1}$-values below the threshold. For the sectors Electric power generation, transmission and distribution; Food, beverage and tobacco; Natural gas distribution and Oil and gas extraction we cannot find a threshold value. For the sector Fabricated Metal, we can only find significant results if the level of significance is extended to $10 \%$ and trimming to $10 \%$. The model was estimated with EViews 11 . 


\section{Modeling hysteresis in the normal rate of capacity utilization}

\subsection{An ABM of hysteresis in the normal rate of capacity utilization}

Capacity utilization, normal as well as actual, is ultimately determined at firm-level. In line with the Steindlian perspective (Steindl, 1952; Lavoie et al., 2004), we treat the normal rate of capacity utilization as a firm-specific convention, while the actual rate of capacity utilization is regarded as an object of exogenous fluctuations (Lavoie, 1996). Based on these premises, in this section we build a simple agent-based model that starts from the individual level. Our objectives are threefold. First, we want to show how firm-level decisions about capacity utilization transmit to the sectoral rate of capacity utilization. Second, by using a calibrated ABM, we want to see whether or not hysteretic dynamics at firm-level give rise to realistic results at the more aggregated (sectoral and macroeconomic) level. Finally, we want to examine the implications of our analysis for the relationship between $u_{n}$ and $u$.

The model consists of 20,000 firms distributed across 25 manufacturing sectors according to the relative importance weights (RIW) of these sectors in the US economy (see table 9 and descriptions for further details). The sectors we consider are the same as those to which we appealed in the previous section. The RIW were taken from Setterfield (2019). As described, firms adjust their normal rate of capacity utilization depending on the volatility of the actual capacity utilization rate, as in figure 1. For the sake of simplicity, only firms are considered in our model. The rest of the economy (households, the financial sector, the primary and tertiary sectors, and the foreign and public sectors) are not explicitly modeled. Demand for output and the actual rate of capacity utilization are not formally considered in our stylized model. Instead, we assume for simplicity that the demand for output is adequately represented by the volatility of the actual rate of utilization, which is our exogenous input variable. The actual rate of capacity utilization for each firm is assumed to gravitate around the firm-specific normal rate of utilization, such that the normal rate of utilization might be treated, for empirical purposes, 
as a time-trend of the actual rate of capacity utilization.

At the beginning of each period, each firm $i(i=1 ; \ldots ; 20,000)$ in each sector $j(j=1 ; \ldots ; 25)$ receives an exogenous and sector-specific volatility shock, $\sigma_{t}^{i, j}$. A period in the model is regarded as corresponding to one calendar year. $\sigma_{t}^{i, j}$ is a random draw from a sector-specific log-normal distribution. The distributions are fitted to the empirical data available on each of the above-mentioned sectors of the US economy, taken from the period 1972 to 2018 . The data further reveals that these sectors do not act independently of each other. Fluctuations in the demand for the goods of one sector cause fluctuations in the demand for goods in other sectors. Therefore, the log-normal distributions, from which the values of $\sigma_{t}^{i, j}$ are drawn, reflect not only the sector-specific log-normal distribution of volatility in actual capacity (exogenous demand) but also the correlation structure between sectors for the period 1972 to 2018 . In other words, $\sigma_{t}^{i, j}$ is a random, sector-specific variable drawn from a multivariate log-normal distribution. Tables 5 to 9 in the Appendix show the necessary parameters for the log-normal distributions and the correlation matrix. In what follows, we assume that $\sigma_{t}^{i, j}=\sigma_{t}^{j}$ for all firms in a specific sector $j$.

Figure 2: Model of genuine hysteresis in capacity utilization for each firm $i$ in sector $j$

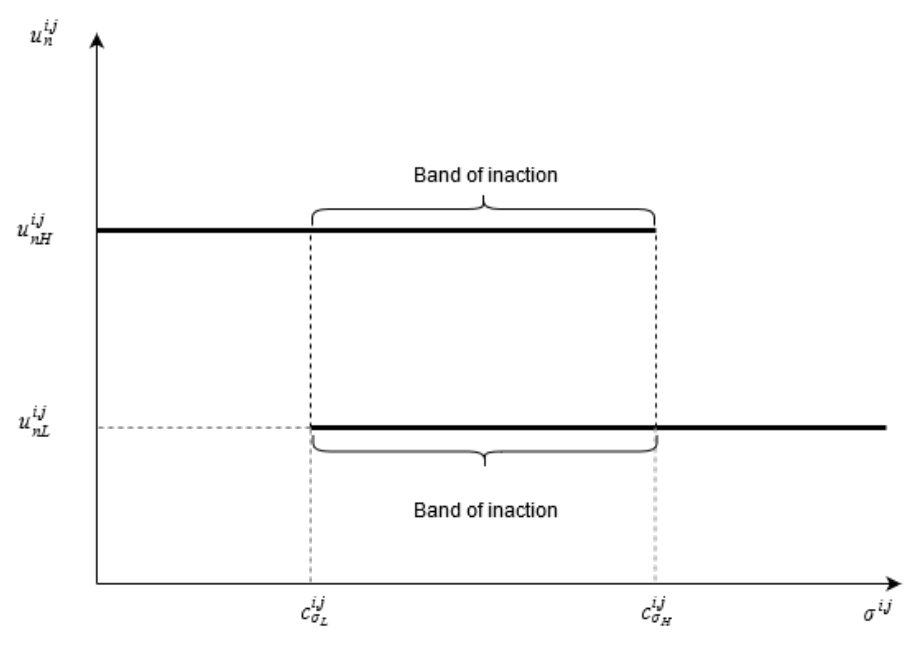

Once they receive the volatility shock $\sigma_{t}^{i, j}$, firms decide on $u_{n}\left(u_{n}=\left\{u_{n L}^{i, j} ; u_{n H}^{i, j}\right\}\right)$ based on 
consideration of $c_{\sigma H}^{i, j}$ and $c_{\sigma L}^{i, j}$, the upper and lower critical values of $\sigma^{i, j}$, as in figure 2. The firm-specific variables, $u_{n L}^{i, j}, u_{n H}^{i, j}, c_{\sigma H}^{i, j}$ and $c_{\sigma L}^{i, j}$, follow the sector-specific levels. We assume that all firms in a sector have the same $u_{n H}$ and $u_{n L}$, as specified in equations (7) and (8) below. These are the maximum and minimum of the (sectoral) normal rate of capacity utilization in each sector. The rationale behind this is that the sectoral maximum (minimum) of $u_{n}$ is attained when all firms adjusted their normal rate of capacity utilization towards $u_{n H}^{i, j}\left(u_{n L}^{i, j}\right)$ :

$$
\begin{gathered}
u_{n L}^{i, j}=u_{n L}^{j} \\
u_{n H}^{i, j}=u_{n H}^{j}
\end{gathered}
$$

The critical values of $\sigma$ are described as follows:

$$
\begin{array}{r}
c_{\sigma H}^{i, j}=c_{\sigma}^{j}+\gamma_{U}^{i, j} \text { with } \gamma_{U}^{i, j} \sim U\left(0,\left(H^{j}-c_{\sigma}^{j}\right)\right) \text { and } H^{j}=c_{\sigma}^{j}+\chi^{U j} \\
c_{\sigma L}^{i, j}=L^{j}+\gamma_{L}^{i, j} \text { with } \gamma_{L}^{i, j} \sim U\left(0,\left(c_{\sigma}^{j}-L^{j}\right)\right) \text { and } L^{j}=\max \left[0.1 ; c_{\sigma}^{j}-\chi^{L j}\right]
\end{array}
$$

In equation 9 , each firm sets its upper critical value $\left(c_{\sigma H}^{i, j}\right)$ to the sector-specific threshold value of $c_{\sigma}^{j}$, taken from table 2, plus a random firm-specific mark-up, which is assumed to be uniformly distributed. A similar procedure is used to find the lower critical value, $c_{\sigma L}^{i, j}$, by making sure that the lower critical value cannot exceed the upper critical value, and that the lower bound cannot be negative (we set a lower limit of 0.1 - see equation (10)). Since adjustment of utilization is expensive (and its purpose uncertain), firms are likely reluctant to adjust $u_{n}^{i, j}$ if there is just a single period for which $\sigma_{t-1}^{i, j}$ lies above or below the critical values. Instead, firms are treated as adjusting $u_{n}$ if the average value of $\sigma^{i, j}$ in the most recent $m$ (respectively 
z) periods lies above (below) the critical values:

$$
\begin{gathered}
\frac{1}{m} \sum_{l=1}^{m} \sigma_{t-l}^{i, j}>c_{\sigma H}^{i, j} \\
\frac{1}{z} \sum_{l=1}^{z} \sigma_{t-l}^{i, j}<c_{\sigma L}^{i, j}
\end{gathered}
$$

where the parameters $m$ and $z$ (respectively) represent the average number of periods required for a firm in any given sector to decide that observed volatility exceeds (falls below) the threshold value necessary to induce a change in the normal rate of capacity utilization to $u_{n L}\left(u_{n H}\right)$ in figure 2. The number of periods $m$ and $z$ considered by firms is sector- and regime-specific, but in general satisfies $m<z$. This is because firms are understood to adjust $u_{n}$ quickly to $u_{n L}$ when they see signs of higher volatility (increased uncertainty) consistent with the onset of a crisis. However, firms only slowly adjust to states of tranquility (i.e., the low volatlity and hence reduced uncertainty environment characteristic of long booms). This behavior accounts for the fact that, as in equations (11) and [12), firms respond more quickly to the onset of crises as confidence is fractured, whereas pessimistic perceptions are persistent (consistent with the process of 'forgetting the last crisis' taking longer than the reaction to its onset), so that the recovery of 'boom time' thinking and behavior is delayed as confidence is only gradually restored (Irons, 2009).

In summary, in each period, each firm receives an exogenous volatility shock $\sigma^{i, j}$ and, depending on whether the average of recent values of $\sigma$ exceeds (falls below) the critical value $c_{\sigma H}$ $\left(c_{\sigma L}\right)$, adjusts $u_{n}$ accordingly. Figure 3 illustrates the decision-making process of each firm with respect to $u_{n}^{i, j}$. The calibration of the model is described in detail in section 7.4 of the Appendix. 
Figure 3: Choice of $u_{n}$ : the $i^{\text {th }}$ firm's decision tree

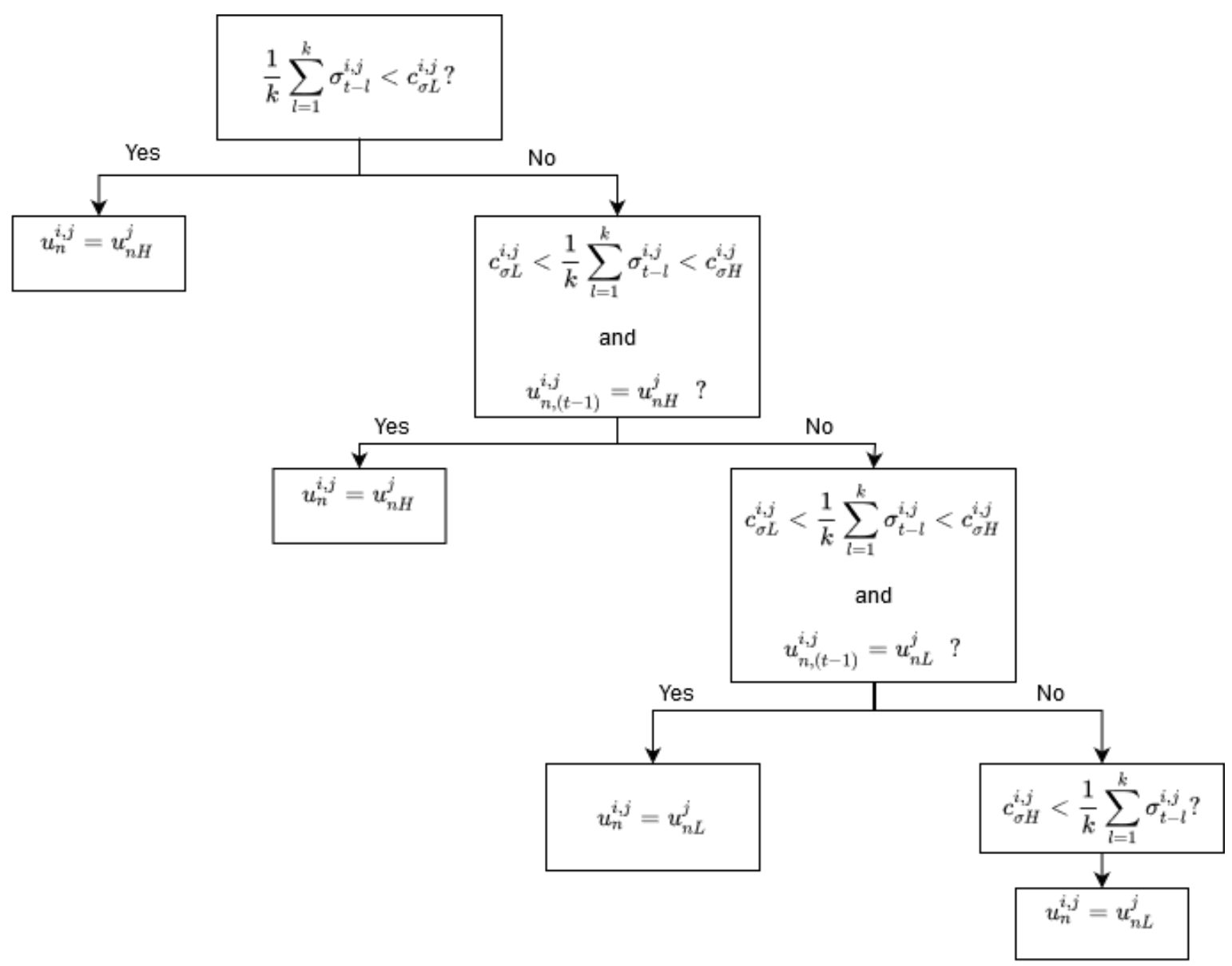

Description: $u_{n}, u_{n L}, u_{n H}, c_{\sigma_{L}} c_{\sigma_{H}}$ are as described above. $u_{n}(t-1)$ describes $u_{n}^{i, j}$ in the previous period. $\sigma$ denotes the current (exogenous) volatility. Each firm computes the average $\sigma$ over k preceding periods (m or z, depending on state of economy). The firm decides on its normal rate of capacity utilization, following the decision tree (figure 3), starting in the upper left part of the figure. 


\subsection{Comparing empirical to artificial data}

Table 3 shows the performance of the model when compared to the empirical data. It shows the results of the discrete threshold regression model and the average values of our proxy for $u_{n}$ for the empirical sectoral data (as previously reported in table 2) compared to the calibrated model, as described in section 4.1. The model was (simultaneously) simulated for 20,000 firms spread over 25 sectors, with their specific values for $u_{n L}^{i, j}, u_{n H}^{i, j}, c_{\sigma L}^{i, j}$ and $c_{\sigma H}^{i, j}$, for 400 consecutive periods. The values for the threshold regressions using the model output were computed over the periods 50 to 400, to account for 'burn-in' periods 16 The sector-specific values for $\sigma_{t}^{j}$ are random realizations from multivariate log-normal distributions, as described above and in more detail in section 7.4 in the Appendix. The artificial data depicts the average values calculated over 100 runs, i.e. 100 different random seeds.

Given its coarse-grained calibration ${ }^{17}$ the model has significant explanatory power for observed patterns on the industry-level, since we are able to reproduce the aggregate patterns in the empirical data. We observe two normal rate of capacity utilization regimes separated by a single break point in $\sigma^{j}$, starting from a model in which firms behave according to the non-ideal relay based on two break points (as in figure 2). In most cases the model also does a good job of capturing the actual values of variables derived from the discrete threshold regression model estimated using the empirical data (see, for example, the Electrical equipment, appliance, and component, Crude processing or Machinery sectors). Finally, the average values of the sectoral normal rate of capacity utilization are close to the empirical values.

\footnotetext{
${ }^{16}$ Similar to Monte-Carlo simulations, ABM in practice considers burn-in periods. The system needs a certain number of periods to adjust to its normal or average behavior, for example the average normal rate of capacity utilization.

${ }^{17}$ The reader is again referred to section 7.4 in the Appendix.
} 
Table 3: Results of the discrete threshold regression model (empirical vs. artificial time series) and average $u_{n}$

\begin{tabular}{|c|c|c|c|c|c|c|c|c|}
\hline & $\begin{array}{l}\text { Empirical } \\
\text { Data }\end{array}$ & & & & $\begin{array}{l}\text { Artificial } \\
\text { Data }\end{array}$ & & & \\
\hline Sector & $C_{1}$ & $C_{2}$ & $\begin{array}{l}\text { Threshold } \\
\left(\sigma_{t-1}\right)\end{array}$ & $\begin{array}{l}\text { Average } \\
u_{n}\end{array}$ & $C_{1}$ & $C_{2}$ & $\begin{array}{l}\text { Threshold } \\
\left(\sigma_{t-1}\right)\end{array}$ & $\begin{array}{l}\text { Average } \\
u_{n}\end{array}$ \\
\hline Apparel and leather goods & 80.84 & 75.72 & 1.23 & 76.78 & 79.67 & 76.49 & 1.65 & 78.37 \\
\hline Chemical & 78.54 & 75.05 & 1.24 & 77.00 & 78.41 & 75.05 & 1.54 & 77.54 \\
\hline $\begin{array}{l}\text { Computer and } \\
\text { electronic product }\end{array}$ & 79.18 & 73.08 & 2.01 & 77.81 & 79.30 & 75.98 & 2.06 & 78.67 \\
\hline $\begin{array}{l}\text { Computers, communications } \\
\text { equipment, and } \\
\text { semiconductors }\end{array}$ & 78.61 & 72.85 & 2.57 & 77.56 & 81.06 & 75.12 & 2.79 & 79.88 \\
\hline Crude processing & 86.90 & 84.74 & 1.65 & 86.30 & 86.70 & 84.68 & 1.88 & 86.29 \\
\hline Electrical equipment, appliance, and component & 84.69 & 80.85 & 1.45 & 82.51 & 84.40 & 80.99 & 1.56 & 85.97 \\
\hline $\begin{array}{l}\text { Electric power generation, } \\
\text { transmission and distribution }\end{array}$ & - & - & 1.74 & 87.13 & 89.83 & 85.14 & 1.78 & 88.32 \\
\hline Fabricated metal product & 78.33 & 73.58 & 2.16 & 77.94 & 77.91 & 76.25 & 1.67 & 78.44 \\
\hline Food, beverage and tobacco & - & - & 0.81 & 80.77 & 80.68 & 79.87 & 0.87 & 80.45 \\
\hline Furniture and related products & 78.88 & 75.36 & 1.59 & 77.56 & 78.16 & 73.06 & 2.04 & 77.20 \\
\hline Machinery & 79.17 & 72.20 & 2.66 & 78.11 & 79.65 & 74.99 & 2.58 & 78.55 \\
\hline Mining & 88.37 & 85.90 & 1.53 & 87.34 & 87.98 & 85.80 & 1.92 & 87.44 \\
\hline Miscellaneous & 77.58 & 75.25 & 1.12 & 76.59 & 77.53 & 75.19 & 1.46 & 77.00 \\
\hline Motor vehicles and parts & 78.62 & 69.15 & 4.31 & 75.41 & 78.38 & 69.06 & 4.73 & 76.49 \\
\hline Natural gas distribution & - & - & 3.64 & 80.68 & 83.39 & 80.23 & 4.01 & 79.74 \\
\hline Non-metallic mineral product & 84.73 & 77.51 & 3.13 & 83.12 & 84.19 & 80.53 & 3.15 & 83.51 \\
\hline Oil and gas extraction & - & - & 1.08 & 92.89 & 93.39 & 92.79 & 1.27 & 92.86 \\
\hline Paper & 88.10 & 86.08 & 1.23 & 86.91 & 88.13 & 86.30 & 1.45 & 87.36 \\
\hline Petroleum and coal products & 87.15 & 80.91 & 1.87 & 85.54 & 87.44 & 83.13 & 1.99 & 86.37 \\
\hline Plastics and rubber products & 85.18 & 79.33 & 1.36 & 82.29 & 83.25 & 77.19 & 1.85 & 85.35 \\
\hline Primary metal & 81.26 & 74.55 & 3.52 & 78.77 & 82.77 & 75.09 & 3.74 & 81.07 \\
\hline $\begin{array}{l}\text { Printing andrRelated } \\
\text { support activities }\end{array}$ & 81.57 & 77.20 & 1.30 & 80.43 & 82.45 & 78.97 & 1.37 & 80.96 \\
\hline Textiles and products & 81.16 & 76.27 & 1.82 & 79.45 & 80.65 & 76.41 & 2.20 & 79.53 \\
\hline Transportation equipment & 75.99 & 68.41 & 3.30 & 74.82 & 76.21 & 74.54 & 2.45 & 75.65 \\
\hline Wood product & 80.16 & 71.55 & 2.18 & 77.14 & 78.90 & 71.38 & 2.77 & 77.20 \\
\hline
\end{tabular}

Source: Own calculations and simulations. The values for the empirical Data was taken from table 2 The threshold values for the four sectors without a threshold in $\sigma_{t-1}$ were approximated with the mean. The artificial data was simulated via Netlog and computed via R-Studio. The values are the average values of 100 runs.

\subsection{Baseline simulations}

Based on the formal description and the calibration, and setting aside the correlation between the volatility of different sectors (i.e. no draw from multivariate log-normal distributions), we can use the model developed so far to simulate a hysteresis loop or 'Ewing loop' (Cross, 1993a) for the aggregate economy, i.e. the macroeconomy. For this purpose, the model is simulated for 20,000 firms (distributed across 25 sectors) for 250 periods and 200 runs. The simulation starts with $\sigma_{0}^{i, j}=0 \forall i, j$, which value is then increased in increments of 0.05 until all firms have 
switched from $u_{n H}$ to $u_{n L}$. The value of $\sigma^{i, j}$ is then decreased incrementally until all firms have switched back. Figure 4 shows the Ewing loop so derived, depicting the (average) normal capacity utilization rate associated with the (average) standard deviation of the actual capacity utilization rate as the latter first rises and then declines. The model replicates the proto-typical form of the Ewing loop (Cross, 1993a, Adamonis and Göcke, 2019). The upper saturation point is $86.4 \%$ and the lower saturation point is $73.6 \%$. These values represent the upper and lower bounds of $u_{n}$ in the simulated aggregate economy, if the correlation structure among the firms is ignored, and are similar to the results (based on FRED data) reported by Setterfield (2019) for the US economy. Hence the model appears to produce plausible results for the US economy, to which it has been benchmarked.

Figure 4: Ewing loop in normal capacity utilization on the macroeconomic level

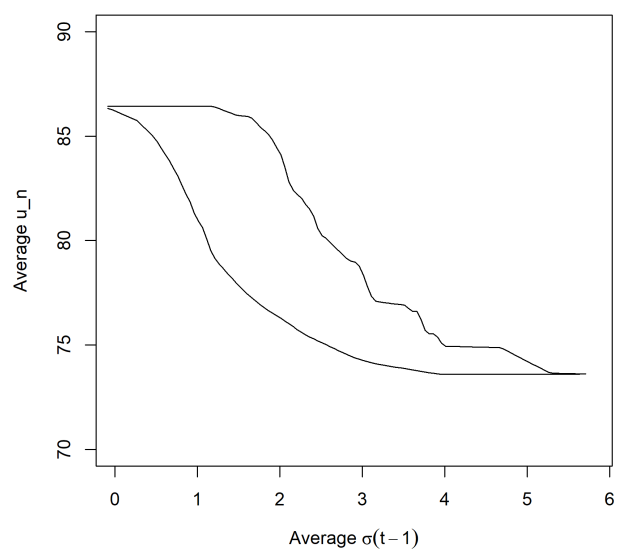

Description: The figure depicts average $u_{n}$ on the macroeconomic level across changing $\sigma$, i.e. the Ewing loop. It depicts the average of 200 runs, i.e. random seeds. For the simulation, all 20,000 firms start with $\sigma_{t}=0.01$ at $\mathrm{t}=0$. $\sigma$ increases uniformly by 0.05 , until all firms have switched to $u_{n L}^{i, j}$. Afterwards, $\sigma$ decreases by 0.05 until all firms switch back to $u_{n H}^{i, j}$. The upper line shows the first periods of increasing volatility and the lower line the periods of decreasing volatility. Cross-correlations of $\sigma$ are ignored.

Figure 5 depicts the macroeconomic time series of $u_{n}$ produced by our model (black line), together with our estimated empirical time series of $u_{n}$ (grey line). The artificial time series is the result of inserting the empirical $\sigma$ of each sector $\left(\sigma_{t}^{j}\right)$ into the model for 47 consecutive 
periods (covering the years 1972 to 2018). The artificial time series is the average over 100 runs. Interestingly, the artificial time series is close to the empirical one. Table 4 reports descriptive statistics for the artificial and the empirical time series. The artificial values are quite close to the empirical ones. Taken together, figure 5 and table 4 show that the output of our model is a reasonable facsimile of the times series it purports to represent.

Figure 5: Time series of the normal capacity utilization on the macroeconomic level

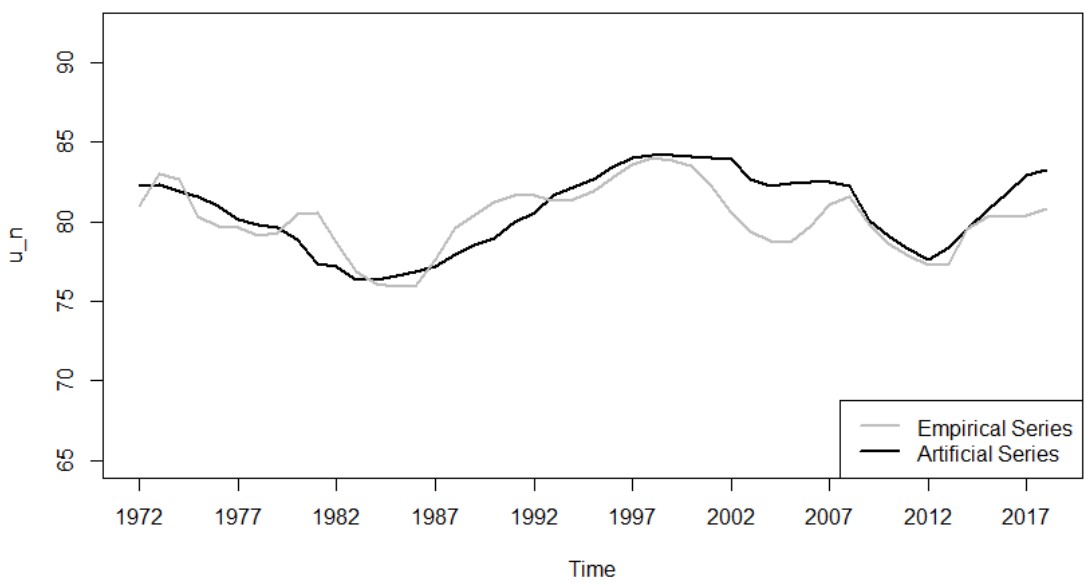

Description: The figure depicts the artificial time series of $u_{n}$ on the macroeconomic level, i.e. simulated model, and the empirical time series between 1972 and 2018 (without linear trend and applying 5-MA-filter). The grey line shows the artificial time series and the black line the empirical time series. The artificial time series was produced by using the empirical $\sigma$ on the sectoral level for 20,000 firms. The artificial series depicts the average over 100 runs, i.e., 100 different random seeds, which affect the thresholds for each firm $\left(c_{\sigma H}^{i, j}, c_{\sigma L}^{i, j}\right)$ but not the series of shocks (the sectoral values of $\sigma$ are the same across runs).

Table 4: Stylized facts of the macroeconomic normal capacity utilization (artificial vs. empirical time series)

\begin{tabular}{|l|r|r|}
\hline & Empirical Time Series & Artificial Time Series \\
\hline Mean $u_{n}$ & 80.16 & 80.67 \\
\hline Standard Deviation of $u_{n}$ & 2.06 & 2.43 \\
\hline Max $u_{n}$ & 84.02 & 84.21 \\
\hline Min $u_{n}$ & 75.90 & 76.34 \\
\hline
\end{tabular}

Description: The table shows the mean, the standard deviation, the maximum and the minimum of $u_{n}$ of the empirical data and the simulated data. The artificial data was produced by 100 runs of the described model. 


\subsection{Bands of the normal capacity utilization rate for individual sectors}

Given the calibration and verification of the model in the previous sections 3 and 4 the model can be used to show the range of values for the normal rate of capacity utilization at the sectoral level. More precisely, by simulating different sequences of within-year volatility shocks for each calendar year, the model predicts a band of values within which the 'true' normal rate of capacity utilization might potentially fluctuate, given the firm-specific critical thresholds and upper and lower values of the normal rate.

For this purpose, the model is simulated separately for each sector for 47 periods ${ }^{18}{ }^{1}$ A total of 250 simulation runs is performed for each sector $[19$ To obtain the range of values for each sectoral normal capacity utilization rate, we abstain from making purely random draws from the sector-specific log-normal distributions of $\sigma_{t}^{i, j}$, as in the simulations performed in section 4.2 . Instead, we assume greater regularity in fluctuations in volatility as observed in the data (Setterfield and Avritzer, 2019; Jurado et al. 2015). Specifically, we model low volatility for around 20 consecutive periods by randomly drawing low values from the sector-specific log-normal distribution to simulate volatility during long booms. We then model high volatility for around five subsequent periods by randomly drawing high values from the sector-specific log-normal distribution to simulate crisis conditions (Setterfield and Avritzer. 2019). Both regimes are simulated with plus (minus) a random draw of $\eta$ periods (with $\eta \sim U[-3 ; 3]$ ) to account for randomness in the duration of long booms and crises. As mentioned above (section 4.1), firms are inclined to respond quickly to crises as confidence is suddenly fractured. Pessimistic perceptions are more persistent, however, consistent with the more drawn-out process of 'forgetting the last crisis'. This delays the recovery of 'boom time' behavior as confidence is only slowly restored (Irons, 2009).

The results of the simulations are depicted in figures 6,7 and 8 as the grey lines. The figures

\footnotetext{
${ }^{18}$ Model is simulated for 121 periods. We present only the last 47 periods of each run. The remaining 74 periods are used as a burn-in phase.

${ }^{19}$ To simulate 250 runs implies to simulate the model for 250 simulations, each with a specific random seed.
} 
further contain the empirical, detrended, time series of the actual rate of capacity utilization, depicted as the black line. The figures show that, typically, the bands are more densely populated in their upper echelons, closer to the upper bound $u_{n H}$. This implies that most industries operate most frequently rather closer to $u_{n H}$ than to $u_{n L}$. To some extent this result is intuitive: by design, our simulations involve long periods of tranquility punctuated by short periods of crisis, so that the frequency of events that might encourage a firm initially operating at $u_{n H}$ to switch to $u_{n L}$ is substantially less than the frequency of events that would encourage the firm to maintain operations at $u_{n H}$. Nevertheless, figures 6, 7 and 8 exhibit considerable heterogeneity among sectors with respect to the 'density' of the interval over which $u_{n}$ varies. The computer sector (Computers and electronic products and Computers, communications equipment, and semiconductors), fossil fuel industries (Oil and gas extraction and Natural gas distribution), and the electricity sector (Electrical equipment, appliance, and component and Electric power generation, transmission, and distribution) operate much less frequently at or near to $u_{n L}$ than do other sectors. Meanwhile, some industries operate rather below the upper bound of $u_{n}$, such as Fabricated metal products. This sector is instead characterized by a dense band in the middle of the graphic in figure 6. Notice also that the various industries differ quite substantially with respect to the range of values of $u_{n}$ within which they operate. On the one hand, the normal rates of capacity utilization are generally quite high (i.e. high $u_{n H}$ and high $u_{n L}$ ) among industries that use products from the primary sector, such as the Mining and Paper sectors. However, other industries operate within a much wider range of values of $u_{n}$ (e.g., Plastics and rubber products, Machinery and Non-metallic mineral mining and quarrying). 
Figure 6: Band of normal capacity utilization and upper and lower bound of actual capacity utilization
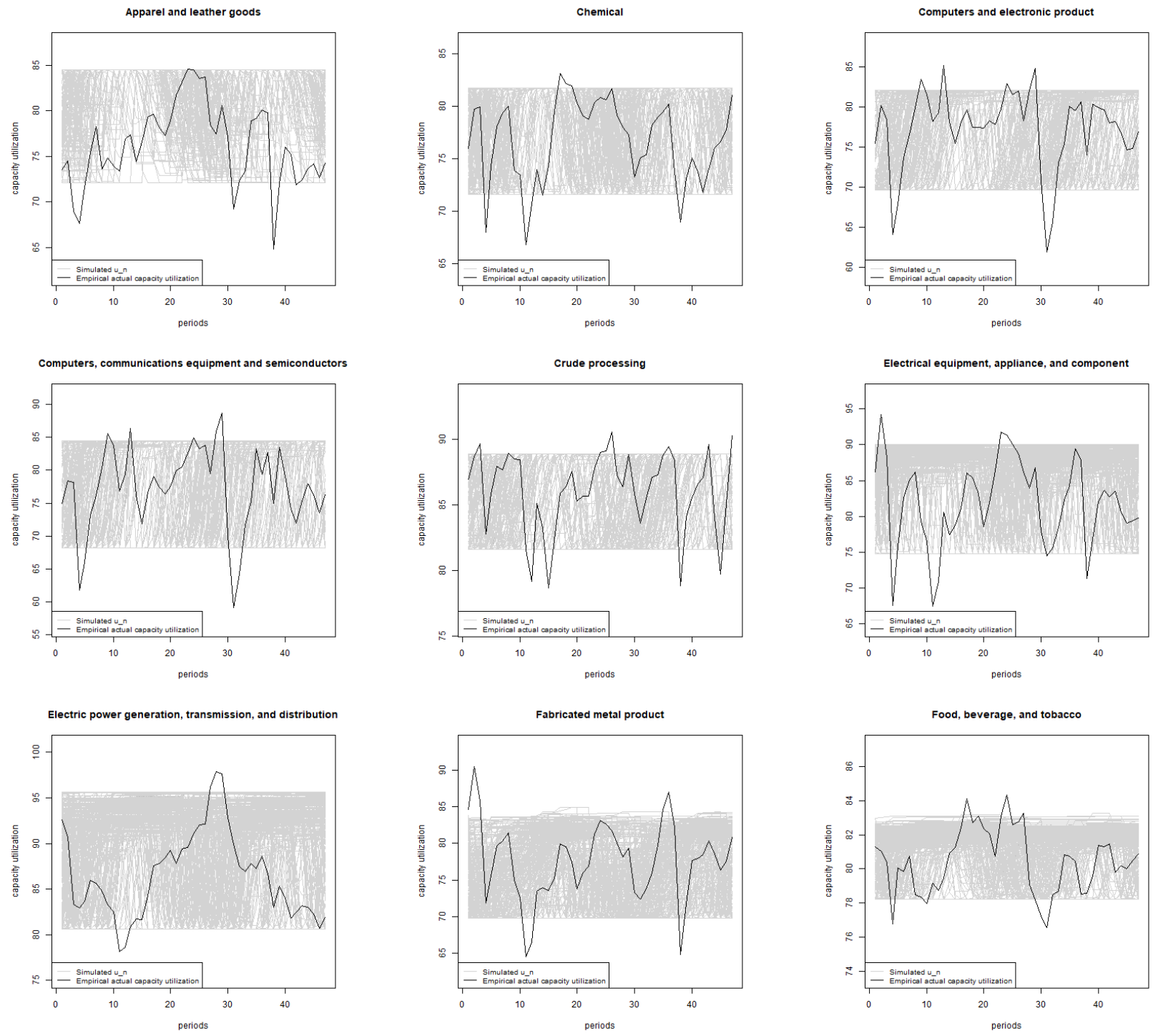

The grey lines show the simulations of the model for each sector. The model was simulated over 47 periods (121 period minus 75 burn-in periods) and 250 random seeds. The black lines show the (detrended) actual rate of capacity utilization. 
Figure 7: Band of normal capacity utilization and upper and lower bound of actual capacity utilization
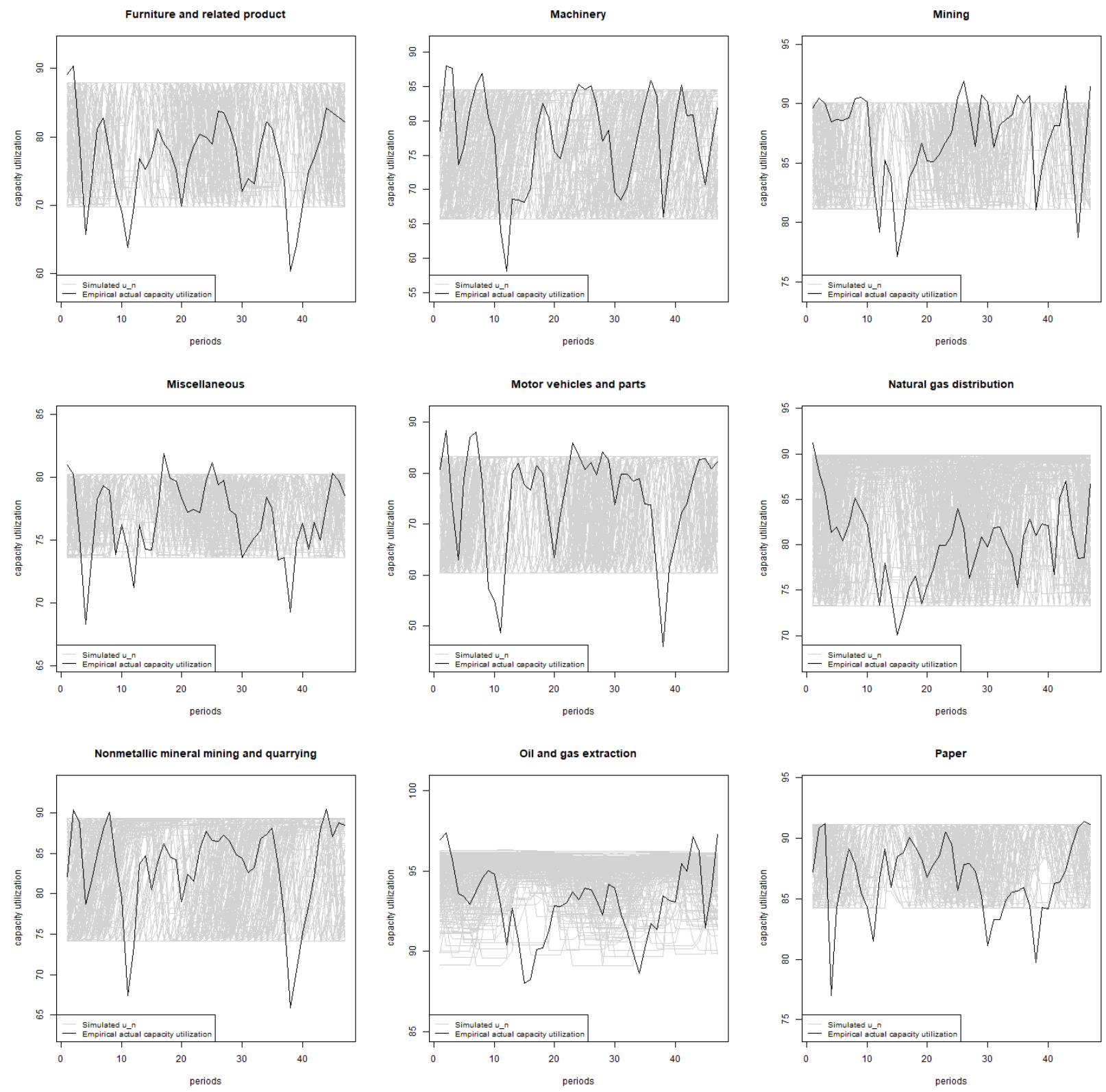

The grey lines show the simulations of the model for each sector. The model was simulated over 47 periods (121 period minus 75 burn-in periods) and 250 random seeds. The black lines show the (detrended) actual rate of capacity utilization. 
Figure 8: Band of normal capacity utilization and upper and lower bound of actual capacity utilization
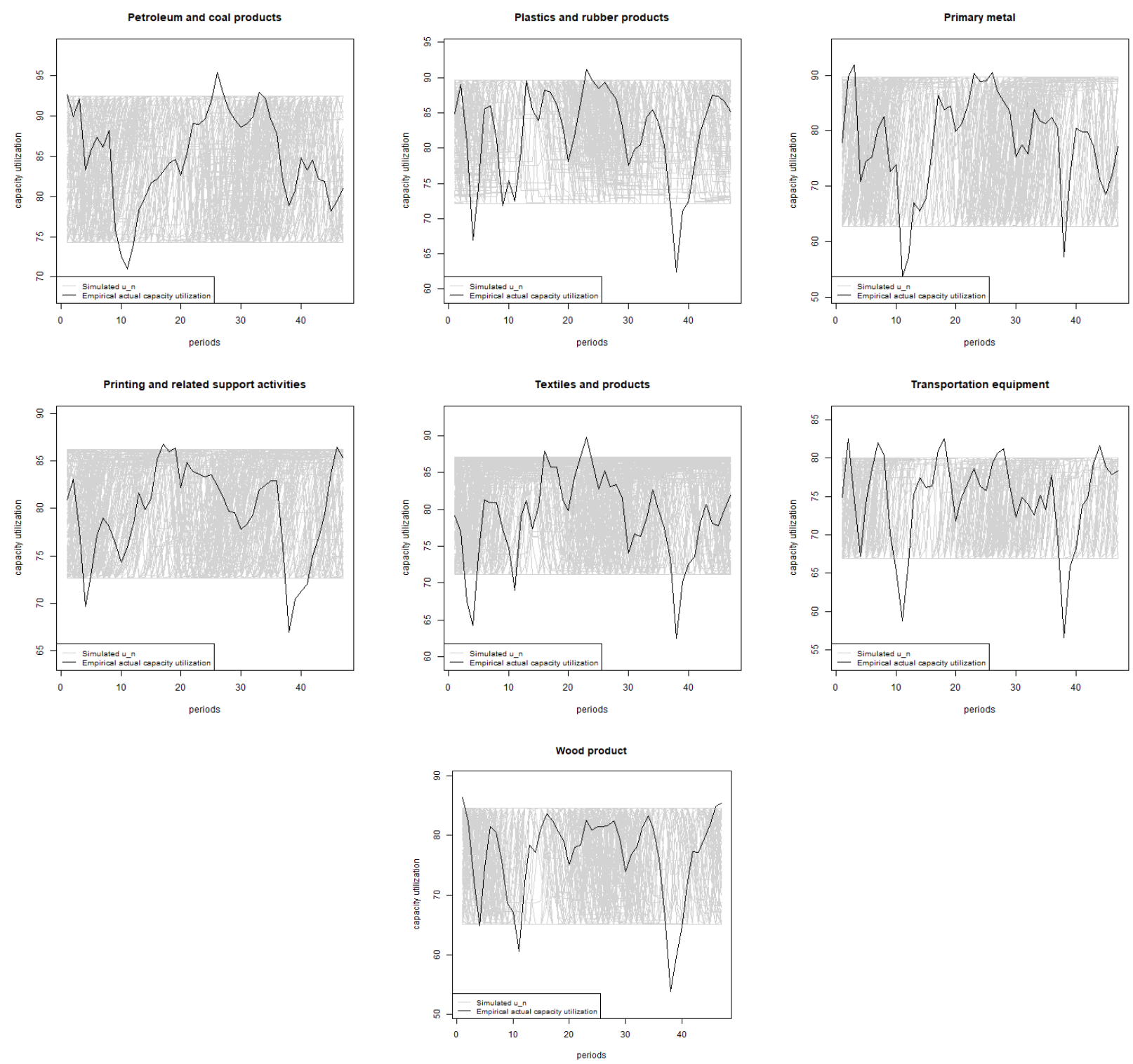

The grey lines show the simulations of the model for each sector. The model was simulated over 47 periods (121 period minus 75 burn-in periods) and 250 random seeds. The black lines show the (detrended) actual rate of capacity utilization. 


\section{Discussion and interpretation}

\subsection{Modeling hysteresis in the normal rate of capacity utilization}

So far, we have modeled genuine hysteresis in a manner that is true to its heterogeneous agent micro-structure: each firm in each sector of the economy is characterized by an idiosyncratic non-ideal relay. The question that might be asked is: to what end? What is the 'payoff' to providing proper microfoundations for the process of hysteresis?

One result of paying attention to the micro-structure of genuine hysteresis is clearly evident from figures 6-8 discrete switching between high and low values of $u_{n}$ at the micro (firm) level creates continuous variation in $u_{n}$ at the sectoral level. In figures $6-8$, this continuous variation is represented by what, by virtue of the number of simulations plotted in each figure, appear as the 'shaded' zones or bands of adjustment of the normal rate. Although not surprising in and of itself, this result (discrete adjustment at the micro-level giving rise to continuous adjustment in the aggregate owing to heterogeneity at the micro level) has important implications. Hence note that our model is behaviorally akin to that of Setterfield and Avritzer (2019) in terms of its microstructure, insofar as the normal rate of utilization at firm-level is strictly single-valued, and can only vary discretely between two (upper and lower) values in response to more or less volatile goods market environments. But our aggregate (sectoral) results are akin to those found in Dutt (2010), Setterfield (2019) and Botte (2019), where $u_{n}=\bar{u}_{n} \pm c$ (where $c$ is some constant) is interpreted as an interval: there is a discrete range within the $\left[\begin{array}{ll}0 & 1\end{array}\right]$ interval within which the normal rate of utilization can be expected to vary. Taken together, both our model and the interval models are consistent with a consensual vision of the possibility of discretely different macrodynamics operating over different ranges of variation in the actual rate of capacity utilization. This is illustrated in figure 9. Figure 9 illustrates three adjustment regimes that can be experienced by an economy that begins at point A with $u_{0}=u_{n}$ : a stable 'Classical' regime where $\dot{u}=f\left(u-u_{n}\right)$ such that $f^{\prime}<0$; an unstable 'Harrodian' regime where $\dot{u}=g\left(u-u_{n}\right)$ such 
that $g^{\prime}>0$; and a hysteretic 'Kaleckian' regime where $\dot{u}_{n}=h\left(u-u_{n}\right)$ with $h^{\prime}>0{ }^{20}$ Now consider an economy beginning at point $\mathrm{A}\left(u_{0}=u_{n}\right)$ that is subject to a shock that displaces the economy to point $\mathrm{B}^{\prime \prime}$ where $u_{1}<u_{0}=u_{n}$. In the Classical regime, $u$ will adjust to $u_{1}^{\prime}=u_{0}=u_{n}$ and in so doing the economy is returned to equilibrium at point $\mathrm{B}^{\prime}=\mathrm{A}$. In the Harrodian regime, $u$ will continue to fall in a series of self-reinforcing adjustments that give expression to Harrodian instability. Finally, in the Kaleckian regime, $u_{n}$ adjusts to $u_{n}^{\prime}=u_{1}$, and equilibrium is restored at point $\mathrm{B}^{\prime \prime}$. In the model developed in this paper, however, $u_{1}=u_{n}^{\prime}$ may represent an outer limit to the Kaleckian regime. If so, any future disturbance that results in $u<u_{1}=u_{n}^{\prime}$ will leave the normal rate of utilization unchanged, and instead be either self-correcting (as $u$ returns to $u_{n}^{\prime}$ in accordance with the Classical dynamic) or self-reinforcing (as $u$ falls ever further below $u_{n}^{\prime}$ in accordance with the Harrodian dynamic). In this way, $u_{n}^{\prime}$ is revealed as a boundary or threshold separating Kaleckian dynamics from qualitatively different Classical and/or Harrodian dynamics, in an economy that may display Classical, Harrodian, or Kaleckian adjustment dynamics over different ranges of variation in the actual rate of capacity utilization.

Unlike interval models of $u_{n}$, however, the 'density' of the interval over which $u_{n}$ varies in figures 6-8 is, itself, variable, and to an extent that differs between sectors of the economy. Hence as previously remarked, in several sectors (see, for example, Electrical equipment, appliance, and component or Computers and electronic product ) this density is observably greater nearer the upper bound of the interval of the normal rate $\left(u_{n H}\right)$ than it is nearer to the lower bound of the interval $\left(u_{n L}\right)$. In other words, in some sectors of the economy and with high frequency (across the number of simulations used to generate the results in figures 6-8), the value of $u_{n}$ typically 'tracks closer' to $u_{n H}$ than to $u_{n L}$, so that the hysteretic value of the normal rate across a large number of simulations 'clusters' closer to $u_{n H}$ than to $u_{n L}$, regardless of the observed variation in $u$. This means that, with relatively high frequency (as compared with sectors

\footnotetext{
${ }^{20}$ Associating these three regimes with the Classical, Harrodian and Kaleckian traditions in macrodynamics serves as a useful shorthand only: the treatment of the normal rate in each of these traditions is richer and more nuanced than our three regimes suggest - as will become clear in the Kaleckian case in section 5.2 below.
} 
Figure 9: Classical, Harrodian and (modified) Kaleckian adjustment

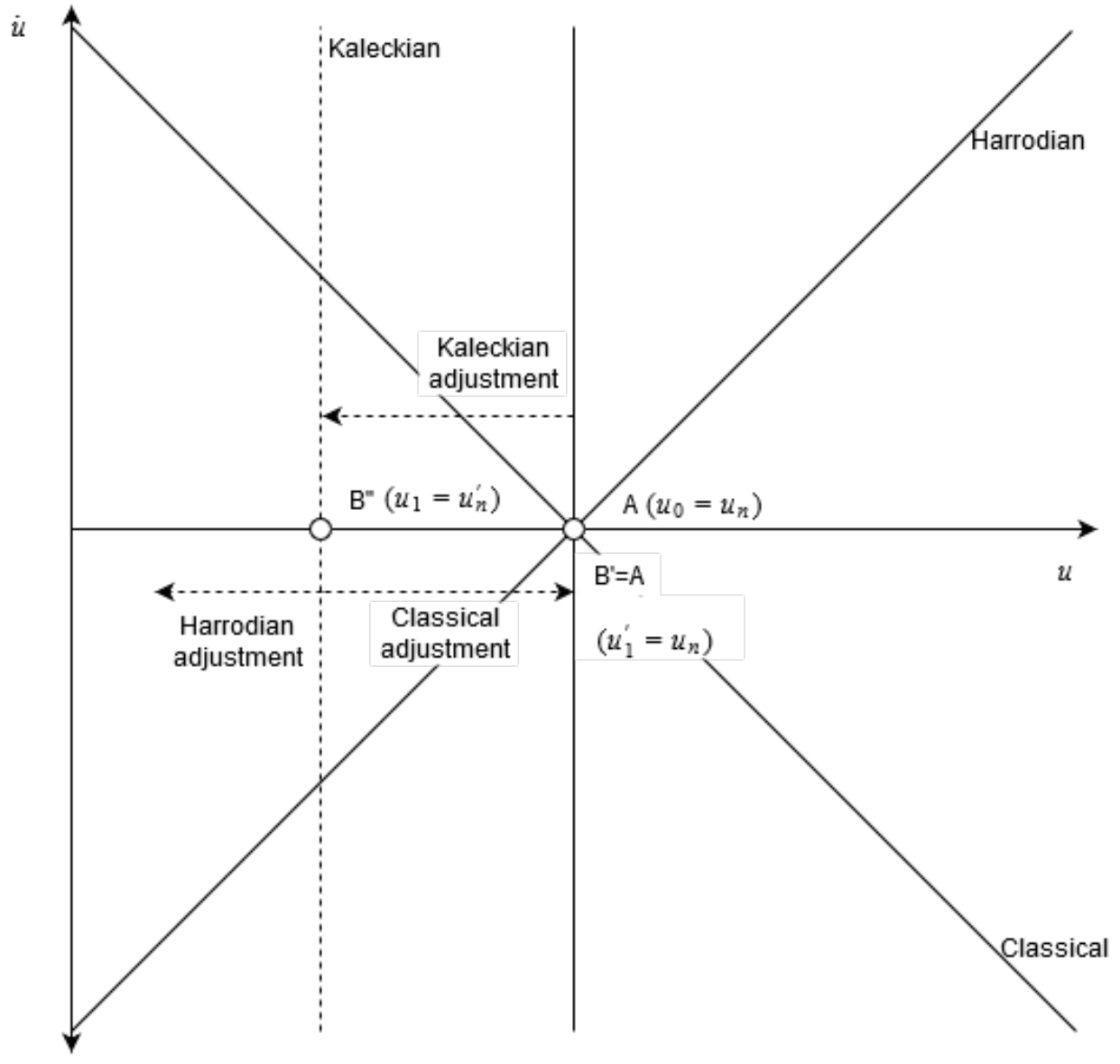


such as Apparel and leather goods or Machinery, where the density of the interval over which $u_{n}$ varies is more uniform over the entire range of the interval), we can expect to observe $u_{n}>u_{n L}$ even as $u_{n L}<u<u_{n}$ for most firms in the sector, indicating a lack of adjustment of $u_{n}$ towards $u$ even within the plausible range of adjustment determined by the interval $u_{n H}-u_{n L}$. This is significant because it suggests a limit to the adjustment of $u_{n}$ within some sectors of the economy that is not predicted by interval models of the natural rate of capacity utilization, which effectively suggest that $u=u_{n}$ is satisfied for all $u$ such that $u_{n L}=\bar{u}_{n}-c \leq u \leq \bar{u}_{n}+c=u_{n H}$.

The observations above point to the value of modeling hysteresis in the normal rate in accordance with genuine hysteresis and in a manner faithful to the precise microfoundations of the latter: substantive results (and their behavioral implications) clearly differ between such a model and either single-sector genuine hysteresis models or interval models of the normal rate.

\subsection{Implications for aggregate structural modeling}

In order to take account of sector-specific dynamics and the possibility of genuine hysteresis in the normal rate of capacity utilization, aggregate structural models should always be augmented by an agent-based block akin to the one developed in this paper. Nevertheless, singlesector aggregate structural models remain popular in macrodynamics and with good reason, given the ease with which they can be manipulated to clearly demonstrate cause-effect interactions between variables in a domain in which causality is the key issue. Recall also that according to Setterfield (2009), it is possible to adopt a 'hybrid' or pragmatic approach to modeling hysteresis based on the methodological question ('how complicated does the model need to be?') associated with authors such as Krugman (2000). The question thus arises: are there lessons from the microfounded model of genuine hysteresis developed in this paper that can be incorporated into single-sector, aggregate structural models, and that would thereby improve 'pragmatic' single sector models of 'hysteresis' based on aggregate, linear difference (or differential) equations? We would argue that there are, so that, to the extent that the debate about 
hysteresis in the normal rate of capacity utilization continues to make use of single-sector models, these models can be improved by reference to the results of and insights developed in this paper.

To begin with, notice that the relationship between $u$ and $u_{n}$ to which the micro-founded dynamics of genuine hysteresis give rise, according to which variations in $u_{n}$ are a subset of observed variations in $u$, can be approximated by the linear structural relation:

$$
\Delta u_{n}=\alpha \Delta u \quad, \quad 0<\alpha<1
$$

where $\alpha$ denotes the 'degree of hysteresis in the normal rate' - i.e., the fraction of any change in the actual rate of utilization between high and low volatility macro regimes that we would usually expect to see reflected in change in the normal rate of capacity utilization. Here, the hysteresis effect is partial, reflecting only some fraction of $\Delta u$.

Now recall that in the literature on the normal rate of capacity utilization, it is common to find two alternative closures:

$$
u_{n}=\bar{u}_{n}
$$

and:

$$
\dot{u}_{n}=\beta\left(u-u_{n}\right)
$$

where, with reference to equation (13), hysteresis is either non-existant ( $\alpha=0$ as in equation (1)) or else complete ( $\alpha=1$ as in equation (2)). But equation (13) recommends a third closure, that reflects the (partial) degree of hysteresis, $\alpha$, and that, in a one-sector structural model, can be captured by simultaneous operation of both:

$$
\dot{u}_{n}=\beta\left(u-u_{n}\right)
$$


and:

$$
\dot{u}=-\gamma\left(u-u_{n}\right)
$$

In this third modified Kaleckian closure, the final change in $u_{n}$ (when the economy is restored to a fully-adjusted steady-state equilibrium) is non-zero but smaller than the initial change in $u$, consistent with the degree of hysteresis being partial $(0<\alpha<1$ in (13)).

Two further comments are now in order. First, the degree of hysteresis can be related to the relative size of the speed of adjustment parameters $\beta$ and $\gamma$ in equations (2) and (14). Suppose, for example, that $\alpha=0.5$, so that following a departure of $u$ from $u_{n}$ creating an initial interval of size $u-u_{n}, u$ and $u_{n}$ adjust so as to eventually 'meet in the middle' of the interval. This will result from identical speeds of adjustment, $\beta=\gamma$. If we were to observe $\alpha=0.33$, meanwhile, $u$ must be adjusting twice as fast towards $u_{n}$ as $u_{n}$ is adjusting towards $u$, so $\gamma=2 \beta$. In general:

$$
\begin{aligned}
& \frac{\beta}{\gamma}=\frac{1-\alpha}{\alpha} \\
& \Rightarrow \alpha=\frac{\gamma}{\beta+\gamma}
\end{aligned}
$$

The degree of hysteresis, $\alpha$, can therefore be inferred from the speeds of adjustment in (2) and (14) and is therefore (in principle) empirically observable.

Second, the operation of the modified Kaleckian closure can - and, indeed, already has been - captured in a suitably-specified one-sector Kaleckian model. Hence consider the simple Kaleckian model:

$$
g=\delta+\eta u
$$




$$
g^{s}=s_{\pi} \pi u
$$

where $g$ is the rate of accumulation, $g^{s}$ is the rate of accumulation consistent with the equality of investment and saving, $s_{\pi}$ denotes the propensity to save from profits and $\pi$ is the profit share of income. Now note that we can write:

$$
\begin{gathered}
\delta=\theta-\eta u_{n} \\
\Rightarrow \dot{\delta}=-\eta \dot{u}_{n}
\end{gathered}
$$

The simultaneous operation of the mechanisms in equations (2) and (19) is illustrated in figure 10. where the model is depicted in an initial state of equilibrium at $u^{*}=u_{n}$, consistent with the growth rate $g^{\prime}$. Now consider an initial increase in $\delta$ from $\delta_{1}$ to $\delta_{2}$ that raises $u$ to $u^{\prime}>u^{*}=u_{n}$. Consistent with (2), the value of $u_{n}$ will begin to rise. But consistent with (19), the value of $\delta$ will begin to fall, shifting the $g$ schedule downwards and, in so doing, reducing the equilibrium value of $u$ towards $u_{n}$. In this way, the response of $\delta$ to $u \neq u_{n}$ in equation 19 brings about variations in $u$ consistent with equation (14). A fully adjusted steady state equilibrium is restored when $\delta=\delta_{3}$, where $u^{\prime \prime}=u_{n}^{\prime}$ at the accompanying growth rate $g^{\prime \prime}$.

The results just demonstrated are identical to those derived by Lavoie (1996, pp.138-142) in the case that he terms 'hysteresis through the investment function only' ${ }^{21}$ This is not surprising since, by substituting equation 18 into equation 16, , we arrive at:

$$
g=\theta+\eta\left(u-u_{n}\right)
$$

which is exactly the form of the investment function used by Lavoie (1996, pp.138-142) W2 We

\footnotetext{
${ }^{21}$ In accordance with this observation, figure 10 is essentially a facsimile of Figure 7 in Lavoie 1996 p.142).

${ }^{22}$ See Lavoie 1996 p.118, equation (2)).
} 
Figure 10: Hysteresis in the normal rate of capacity utilization: the modified Kaleckian closure

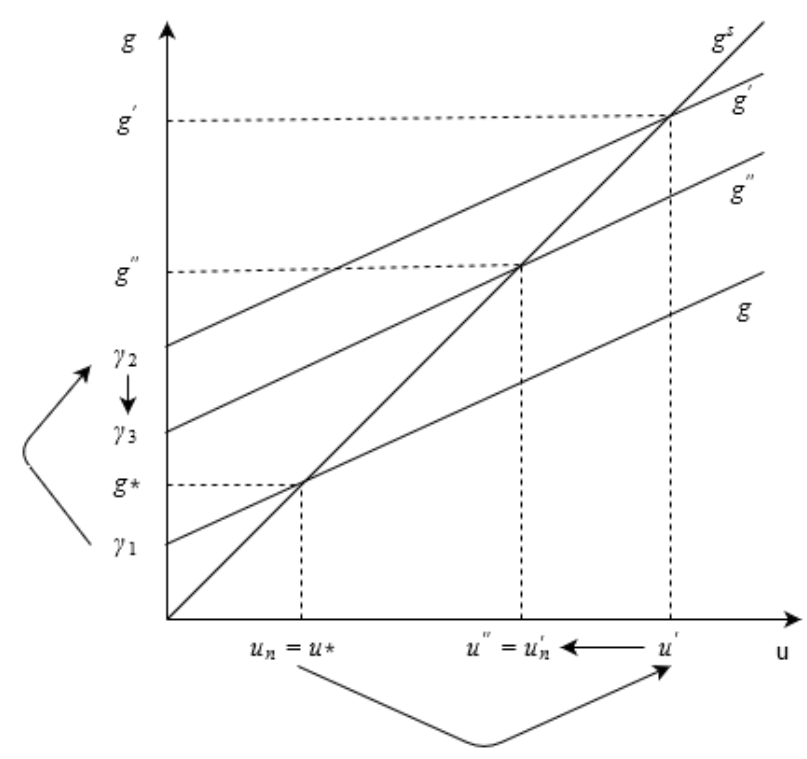

can infer from all this that the case for utilizing one-sector models in Kaleckian macrodynamics and, in the process, approximating hysteresis as a unit- or zero-root process is somewhat stronger than the pragmatic case made by Setterfield (2009). As originally shown by Lavoie (1996, pp.138-142) and as effectively replicated in the argument above, with an investment function in which the rate of accumulation is sensitive to the actual and normal rates of utilization, a one-sector Kaleckian model that is faithful to the basic properties of Kaleckian macrodynamics (the paradoxes of thrift and costs) can also produce partial hysteresis in the normal rate of capacity utilization consistent with the existence of genuine hysteresis in the normal rate ${ }^{23}$

\footnotetext{
${ }^{23}$ It is worth noting here that Lavoie $\sqrt{1996)}$ demonstrates other means of deriving hysteresis in the normal rate of utilization in a one-sector Kaleckian model, but these are not simultaneously faithful to both the basic properties of Kaleckian macrodynamics mentioned above and the property of genuine hysteresis captured by $0<\alpha<1$ in equation 13.
} 


\section{Conclusions}

This paper contributes to the current literature in four respects. First, we find evidence supportive of the hypothesis that there is genuine hysteresis in the normal rate of capacity utilization at sectoral level in the US economy. It should be noted, however, that our analysis provides only partial support for this hypothesis: some sectors of the US economy do not display the statistical regularities consistent with the discrete switching between higher and lower values of the normal rate that can be associated with genuine hysteresis in the latter.

Second, by developing and applying a simple agent-based model, we are able to make suggestions about the industry-specific behaviour of normal rates of capacity utilization. Our model shows that discrete variations in the normal rate of capacity utilization (between'higher'

and 'lower' values $u_{n H}^{i, j}$ and $u_{n L}^{i, j}$ ) at firm-level result in relatively smooth (i.e., continuous) changes in the normal rate at higher levels of aggregation (see figure 5), while preserving the properties of genuine hysteresis observed at the micro level that give rise to the propensity for temporary shock to produce permanent effects. Furthermore, our simulations demonstrate that different sectors of the US economy operate at quite different normal rates of capacity utilization. For example, while some sectors appear to operate at consistently high normal rates, others oscillate within a rather wide range of values. In all cases, however, the ranges of variation in the normal rate of capacity utilization are smaller than the corresponding ranges of variation in the actual rate. This is true even though these ranges of variation are small in some sectors.

Third, our simulation exercises have important implications for heterodox macrodynamics, suggesting that the normal rate of capacity utilization can be considered as partially hysteretic. In particular, our theoretical model produces a corridor of potential values of the normal rate of capacity utilization within which we observe hysteretic variation in the normal rate, and within which the basic mechanisms of Kaleckian macrodynamics can be considered to operate.

Finally, and reflecting more broadly on Post Keynesian macroeconomics as a whole, this 
paper suggests a route towards possible reconciliation of work in the Classical/neo-Keynesian and Kaleckian traditions. Our partial hysteresis result is suggestive of an economy in which both Classical/neo-Keynesian and Kaleckian adjustment mechanisms are operative. In a traditional (one sector) model, this can be captured by disequilibrium dynamics that involve a double and simultaneous adjustment process in which the actual rate of capacity utilization adjusts towards the normal rate and the normal rate of capacity utilization adjusts towards the actual rate. It follows from these observations that the opportunity exists for greater synthesis of these seemingly competing traditions.

These contributions aside, our analysis leaves open various avenues for further investigation and research. For example, our simulation model would benefit from firm-level data that would still more firmly anchor our claims about hysteresis in the normal rate in the empirical properties of the US economy. Furthermore, and as noted in sub-section 5.2, proper integration of genuine hysteresis in the normal rate into Post Keynesian macrodynamics requires augmenting an aggregate structural model with the sort of agent-based block developed in this paper. Only the completion of this task will provide a model of long-run variation in the normal rate of capacity utilization in a manner consistent with the properties of genuine hysteresis. Finally, in addition to calling for further integration of genuine hysteresis into Post Keynesian macrodynamics (consistent with the traditions initiated by both Robinson (1962, chpt. 2) and Kaldor (1972)), our paper suggests that future research should pay more attention to thinking of Classical/neo-Keynesian and Kaleckian macrodynamics as being potentially characteristic of different historical regimes of capitalism, rather than as opposing theories of unvarying (historically uniform) capitalist macrodynamics.

It is also worth remarking that our research has implications for policy. As is well known, variability in the rate of capacity utilization is a necessary condition for the Kaleckian paradox of costs. To the extent that the normal rate of capacity utilization displays hysteresis over a subset of the range of variation in the actual rate of capacity utilization, this suggests that progressive 
policies designed to redistribute income towards wages can be conducive to improved long-run macroeconomic performance that, by simultaneously raising the rate of profit, avoids distributional conflict. Because hysteretic variation in the normal rate of utilization is not universal, however, neither is the argument just made: progressive policies of income redistribution cannot be considered a panacea for modern capitalism. Of course, redressing income inequality is not simply a means to an end. But to the extent that serving the objective of improved longrun macroeconomic performance strengthens the case for redressing income inequality, our paper can be thought of as lending credence to the notion that redistributing income towards wages can be beneficial because of its potentially positive contribution to the performance of the economy. 


\section{References}

Adamonis, J. and M. Göcke (2019). Modelling economic hysteresis losses caused by sunk adjustment costs. Journal Of Post Keynesian Economics 42(2), 299-318.

Amable, B., J. Henry, F. Lordon, and R. Topol (1993). Unit root in the wage-price spiral is not hysteresis in unemployment. Journal of Economic Studies 20(1/2), 123-135.

Amable, B., J. Henry, F. Lordon, and R. Topol (1994). Strong hysteresis versus zero-root dynamics. Economics Letters 44(1-2), 43-47.

Amadeo, E. (1987). Expectations in a steady-state model of capacity utilization. Political Economy: Studies in the Surplus Approach 3(1), 75-89.

Bai, J. and P. Perron (2003). Computation and analysis of multiple structural change models. Journal of Applied Econometrics 18(1), 1-22.

Bassi, F. and D. Lang (2016). Investment hysteresis and potential output: A postKeynesian-Kaleckian agent-based approach. Economic Modelling 52(Part A), 35-49.

Belke, A., A. Oeking, and R. Setzer (2015). Domestic demand, capacity constraints and exporting dynamics: Empirical evidence for vulnerable euro area countries. Economic Modelling 48, $315-325$.

Blanchard, O. and L. Summers (1986). Hysteresis and the European unemployment problem. In NBER Macroeconomics Annual 1986, Volume 1, pp. 15-90. Cambridge, MA: National Bureau of Economic Research, Inc.

Botte, F. (2019). Estimating normal rates of capacity utilization and their tolerable ranges: a comment on Mark Setterfield. Cambridge Journal of Economics (forthcoming).

Cross, R. (1993a). Hysteresis and Post Keynesian Economics. Journal of Post Keynesian Economics 15(3), 305-308.

Cross, R. (1993b). On the foundations of hysteresis in economic systems. Economics and Philosophy 9(1), 53-74.

Dutt, A. K. (1997). Equilibrium, path dependence and hysteresis in post-Keynesian models. In P. Arestis, G. Palma, and M. Sawyer (Eds.), Capital Controversy, Post-Keynesian Economics and the History of Economic Thought: Essays in Honour of Geoff Harcourt. London: Routledge.

Dutt, A. K. (2009). Path dependence, equilibrium and economic growth. In P. Arestis and M. Sawyer (Eds.), Path Dependency in Macroeconomics: International Papers in Political Economy. Houndmills and New York: Palgrave. 
Dutt, A. K. (2010). Equilibrium, stability and path dependence in Post Keynesian models of economic growth. In A. Birolo, D. Foley, H. D. Kurz, B. Schefold, and I. Steedman (Eds.), Production, Distribution and Trade: Alternative Perspectives. Essays in Honour of Sergio Parrinello. London: Routledge.

Eisner, R. (1997). A new view of the NAIRU. In P. Davidson and J. Kregel (Eds.), Improving the Gloabl Economy: Keynesianism and the Growth of Output and Employment. Cheltenham: Edward Elgar.

Fagiolo, G., A. Moneta, and P. Windrum (2007, September). A Critical Guide to Empirical Validation of Agent-Based Models in Economics: Methodologies, Procedures, and Open Problems. Computational Economics 30(3), 195-226.

Fujita, S. (2019). Mark-up pricing, sectoral dynamics, and the traverse process in a two-sector Kaleckian economy. Cambridge Journal of Economics 43(2), 465-479.

Hansen, B. E. (1999). Threshold effects in non-dynamic panels: Estimation, testing, and inference. Journal of Econometrics 93(2), 345-368.

Hargreaves Heap, S. P. (1980). Choosing the wrong 'natural' rate: Accelerating inflation or decelerating employment and growth? The Economic Journal 90(359), 611-620.

Irons, J. (2009). Economic scarring. The long-term impacts of the recession. EPI- Briefing Paper. (243), 17.

Jurado, K., S. C. Ludvigson, and S. Ng (2015). Measuring Uncertainty. American Economic Review 105(3), 1177-1216.

Kaldor, N. (1972). The irrelevance of equilibrium economics. Economic Journal 82(328), 12371255.

Krugman, P. (2000). How complicated does the model have to be? Oxford Review of Economic Policy 16(4), 33-42.

Kurz, H. (1986). Normal positions and capital utilization. Political Economy 2(1), 37-54.

Kurz, H. (1990). Effective demand, employment and capital utilizsation in the short run. Cambridge Journal of Economics 14(2), 205-17.

Lavoie, M. (1995). The Kaleckian model of growth and distribution and its Neo-Ricardian and Neo-Marxian critiques. Cambridge Journal of Economics 19(6), 789-818.

Lavoie, M. (1996). Traverse, hysteresis and normal rates of capacity utilization in kaleckian models of growth and distribution. Review of Radical Political Economics 28(4), 113-147.

Lavoie, M. (2010). Surveying short-run and long-run stability issues with the Kaleckian model of growth. In M. Setterfield (Ed.), Handbook of Alternative Theories of Economic Growth,. Cheltenham, UK: Edward Elgar. 
Lavoie, M., G. Rodríguez, and M. Seccareccia (2004). Similitudes and discrepancies in postKeynesian and Marxist theories of investment: A theoretical and empirical investigation. International Review of Applied Economics 18(2), 127-149.

Mota, P. R., J. Varejão, and P. B. Vasconcelos (2012). Hysteresis In The Dynamics Of Employment. Metroeconomica 63(4), 661-692.

Nikiforos, M. (2013). The (normal) rate of capacity utilization at the firm level. Metroeconomica 64(3), 513-538.

Nikiforos, M. (2016). On the 'utilisation controversy': a theoretical and empirical discussion of the Kaleckian model of growth and distribution. Cambridge Journal of Economics 40(2), 437-467.

Railsback, S. F. and V. Grimm (2011). Agent-Based and Individual-Based Modeling: A Practical Introduction. Princeton, NJ: Princeton University Press.

Robinson, J. (1956). The Accumulation of Capital. London: Macmillan.

Robinson, J. (1962). Essays in the Theory of Economic Growth. London and Basingstoke: Macmillan.

Serrano, F. (1995). Long period effective demand and the Sraffian supermultiplier. Contributions to Political Economy 14, 67-90.

Setterfield, M. (2009). Path dependency, hysteresis and macrodynamics. In P. Arestis and M. Sawyer (Eds.), Path Dependency and Macroeconomics, pp. 37-79. London: Palgrave Macmillan.

Setterfield, M. (2019). Long-run variation in capacity utilization in the presence of a fixed normal rate. Cambridge Journal of Economics 43(2), 443-463.

Setterfield, M. and J. D. Avritzer (2019). Hysteresis in the normal rate of capacity utilization: a behavioural explanation, New School for Social Research, mimeo.

Skott, P. (2010). Growth, instability and cycles: Harrodian and Kaleckian models of accumulation and income distribution. In M. Setterfield (Ed.), Handbook of Alternative Theories of Economic Growth. Cheltenham: Edward Elgar.

Skott, P. (2012). Theoretical and empirical shortcomings of the Kaleckian investment function. Metroeconomica 63(1), 109-138.

Solow, R. (1986). Unemployment: Getting the questions right. Economica 53(Supplement), S23-S34.

Steindl, J. (1952). Maturity and Stagnation in American capitalism. Oxford, UK: Blackwell. 
Trezzini, A. and D. Pignalosa (2021, April). The normal degree of capacity utilization: The history of a controversial concept. Centro Sraffa Working Papers CSWP49, Centro di Ricerche e Documentazione Piero Sraffa. 


\section{Appendix}

\subsection{Sectoral correlation between $\Delta u_{n}$ and $\Delta \sigma_{t-1}$}

Figure 11: Correlation between $\Delta u_{n}$ and $\Delta \sigma_{t-1}$
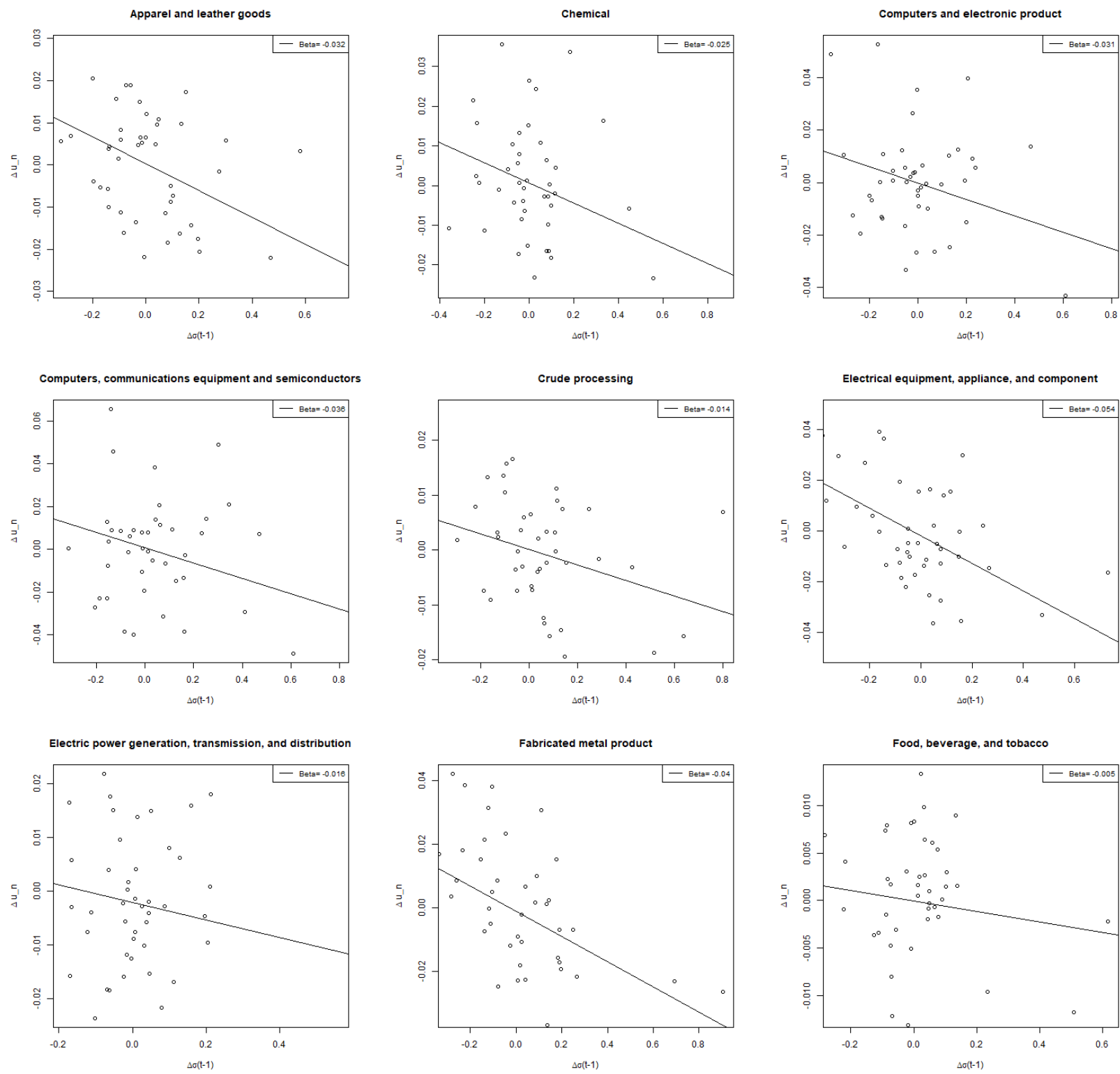

Description: Figures depict the scatter plots for the sector-specific relation between the changes in $u_{n}$ and changes in $\sigma_{t-1}$. They show a negative relationship between both variables for all sectors. The slope parameter $(\beta)$ is always below 1 , which indicates that $u_{n}$ responds to changes in $\sigma_{t-1}$, but to a lower extent than the changes in $\sigma_{t-1}$. 
Figure 12: Correlation between $\Delta u_{n}$ and $\Delta \sigma_{t-1}$ on sectoral level
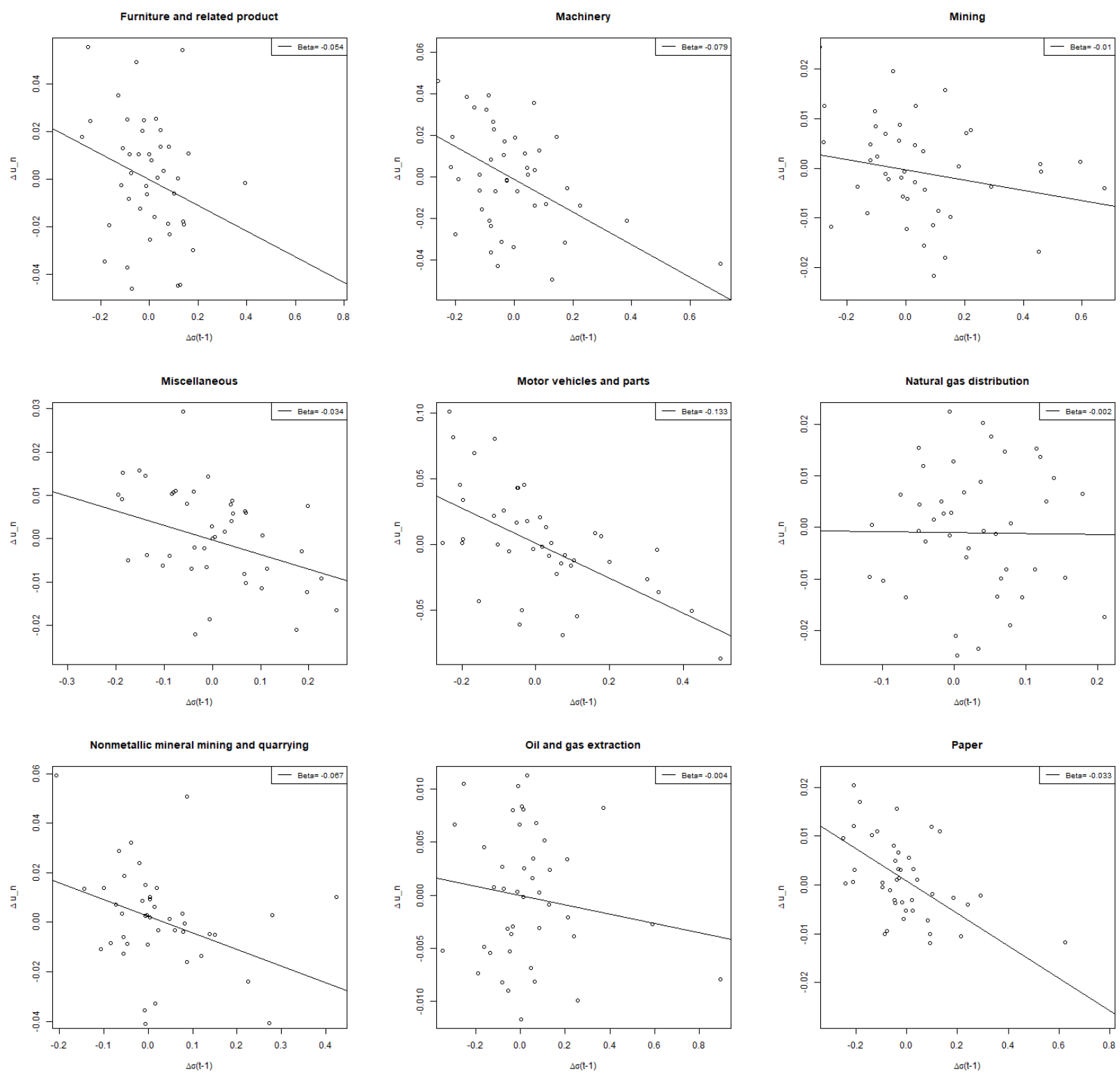

Description: Figures depict the scatter plots for the sector-specific relation between the changes in $u_{n}$ and changes in $\sigma_{t-1}$. They show a negative relationship between both variables for all sectors. The slope parameter $(\beta)$ is always below 1 , which indicates that $u_{n}$ responds to changes in $\sigma_{t-1}$, but to a lower extent than the changes in $\sigma_{t-1}$. 
Figure 13: Correlation between $\Delta u_{n}$ and $\Delta \sigma_{t-1}$ on sectoral and macroeconomic level
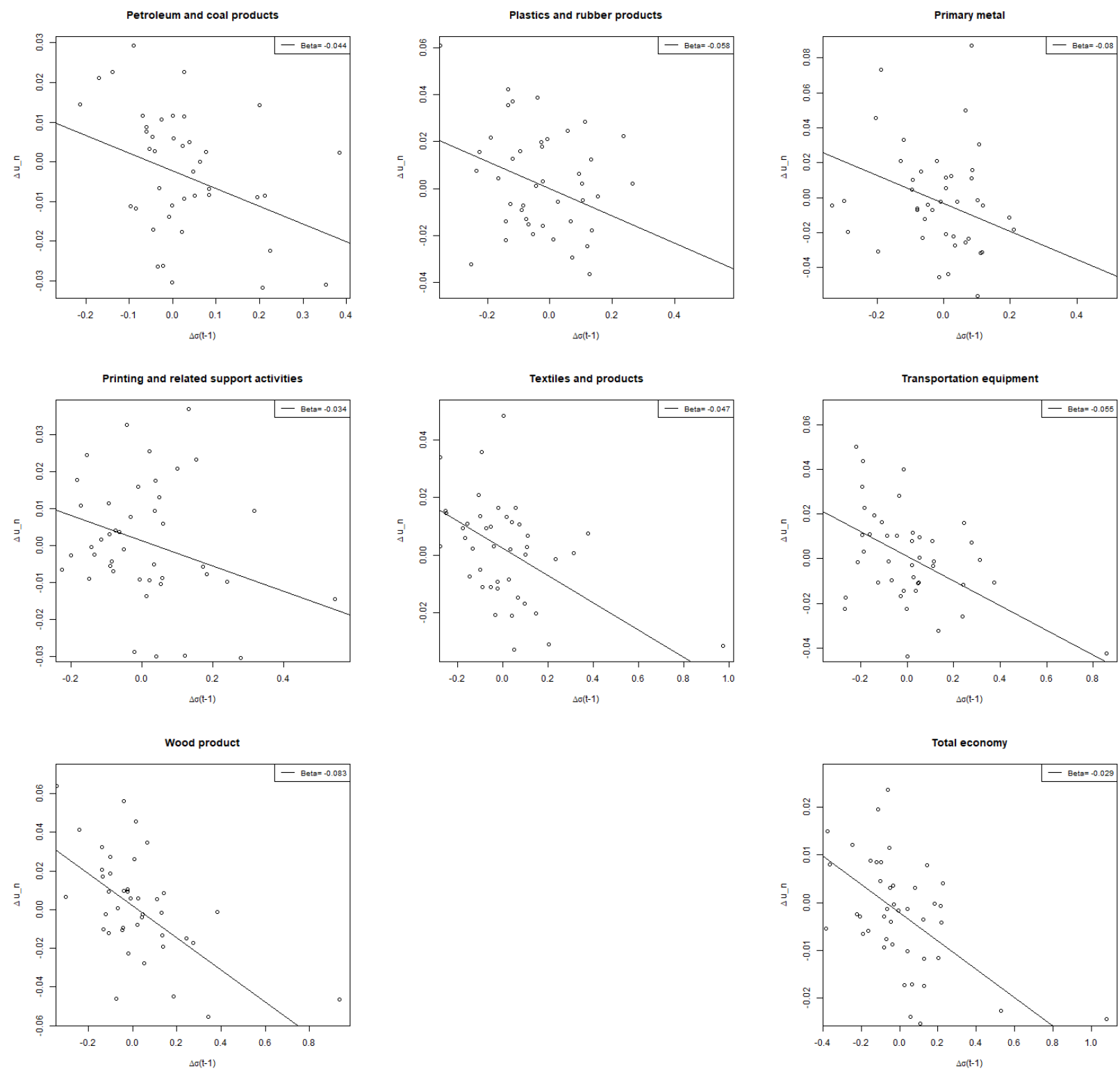

Description: Figures depict the scatter plots for the sector-specific relation between the changes in $u_{n}$ and changes in $\sigma_{t-1}$. They show a negative relationship between both variables for all sectors. The slope parameter $(\beta)$ is always below 1 , which indicates that $u_{n}$ responds to changes in $\sigma_{t-1}$, but to a lower extent than the changes in $\sigma_{t-1}$. 


\subsection{Sectoral scatter plots $u_{n}$ and $\sigma_{t-1}$}

Figure 14: Sectoral scatter plot $u_{n}$ and $\sigma_{t-1}$ (including $u_{n L}$ and $u_{n H}$ )
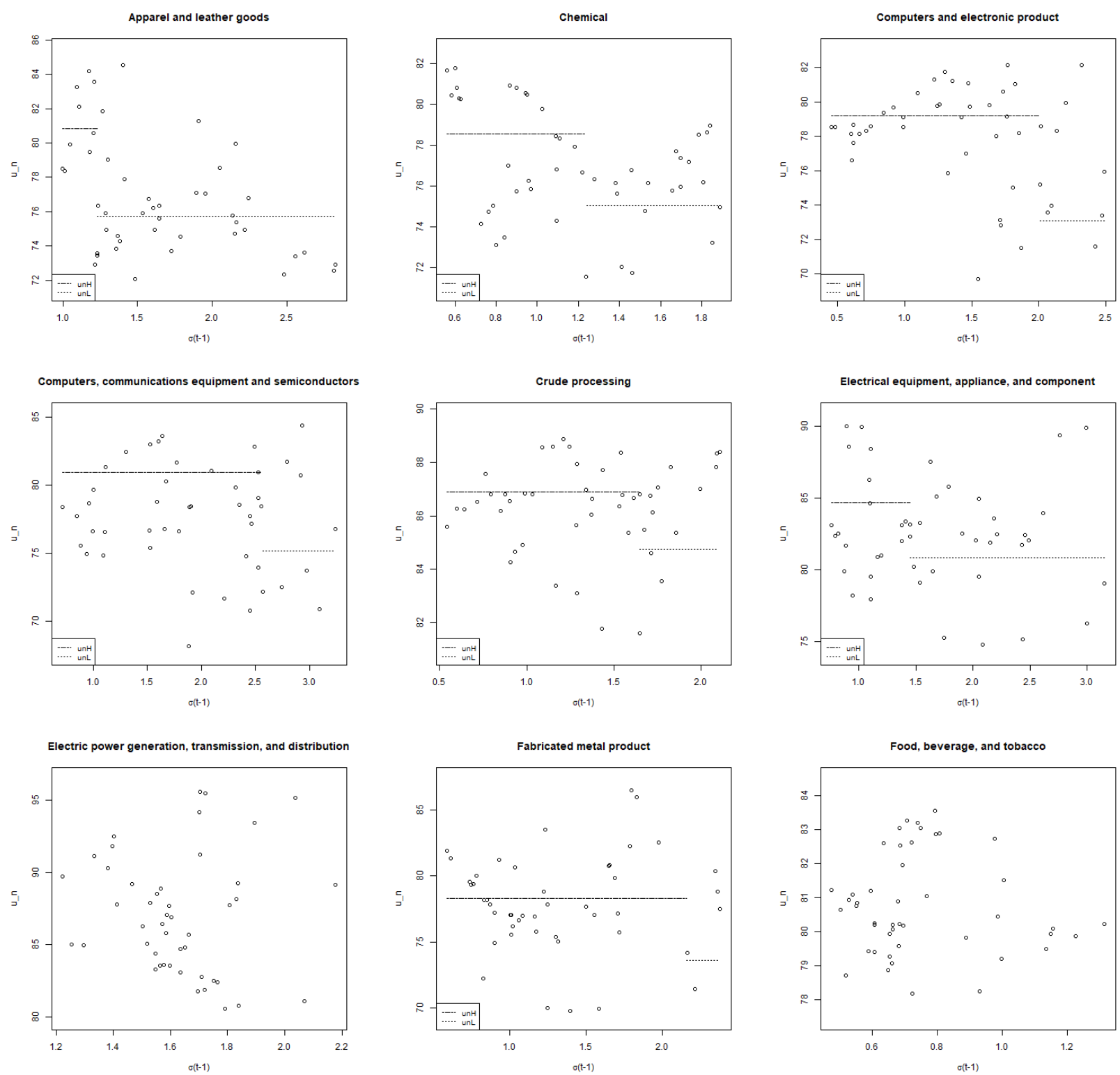

The figures show the scatter plots for the sector-specific $u_{n}$ and $\sigma_{t-1}$. Further, these graphs depicts the upper and lower rate of $u_{n}\left(u_{n H}\right.$ and $\left.u_{n L}\right)$.The sectors Electric power generation, transmission and distribution and Food, beverage and tobacco do not show $u_{n L}$ and $u_{n H}$ because the discrete threshold regression model could not find significant thresholds. 
Figure 15: Sectoral scatter plot $u_{n}$ and $\sigma_{t-1}$ (including $u_{n L}$ and $u_{n H}$ )
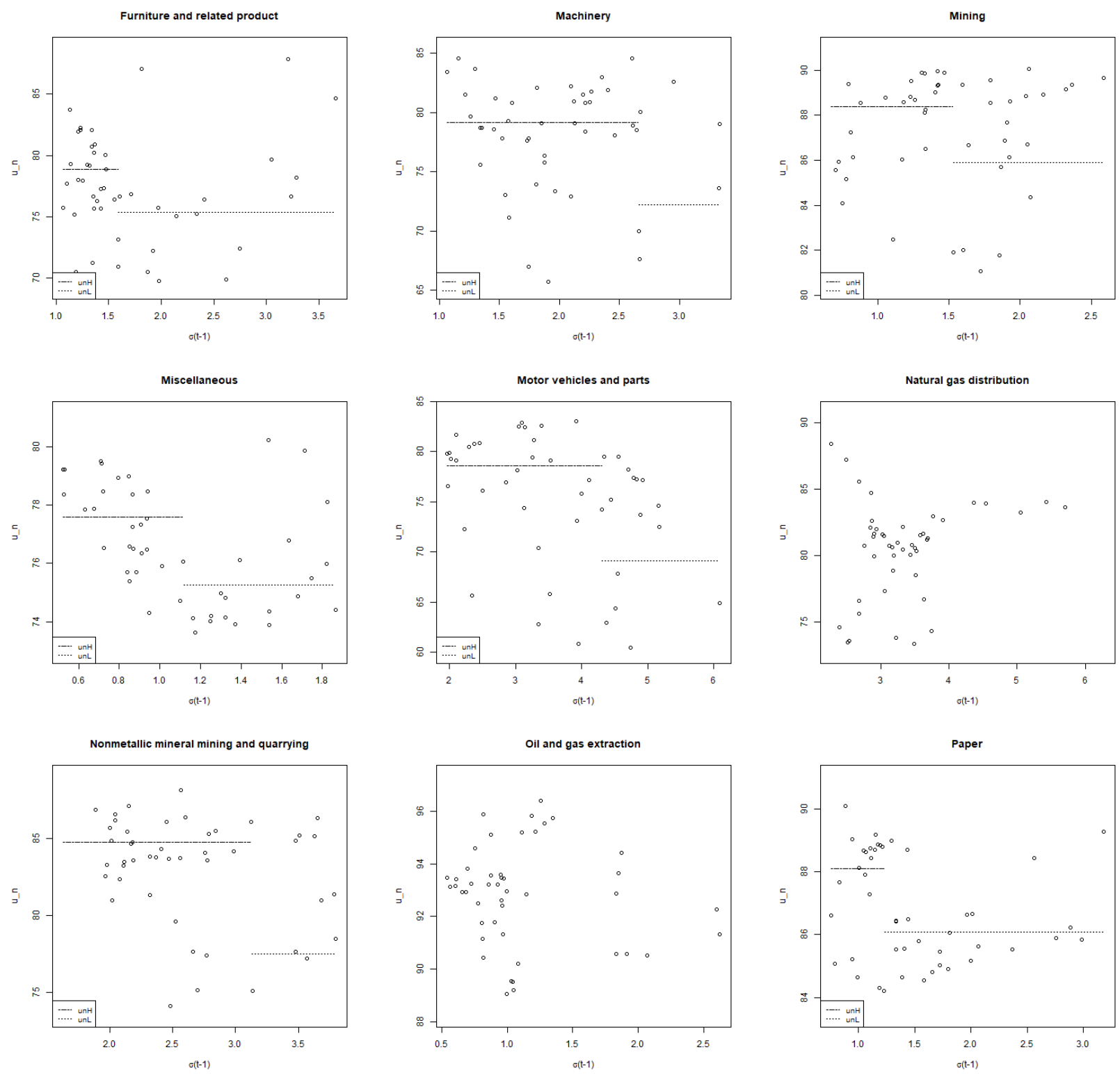

The figures show the scatter plots for the sector-specific $u_{n}$ and $\sigma_{t-1}$. Further, these graphs depicts the upper and lower rate of $u_{n}\left(u_{n H}\right.$ and $\left.u_{n L}\right)$. The sectors Natural gas distribution and Oil and gas extraction do not show $u_{n L}$ and $u_{n H}$ because the discrete threshold regression model could not find significant thresholds. 
Figure 16: Sectoral scatter plot $u_{n}$ and $\sigma_{t-1}$ (including $u_{n L}$ and $u_{n H}$ )
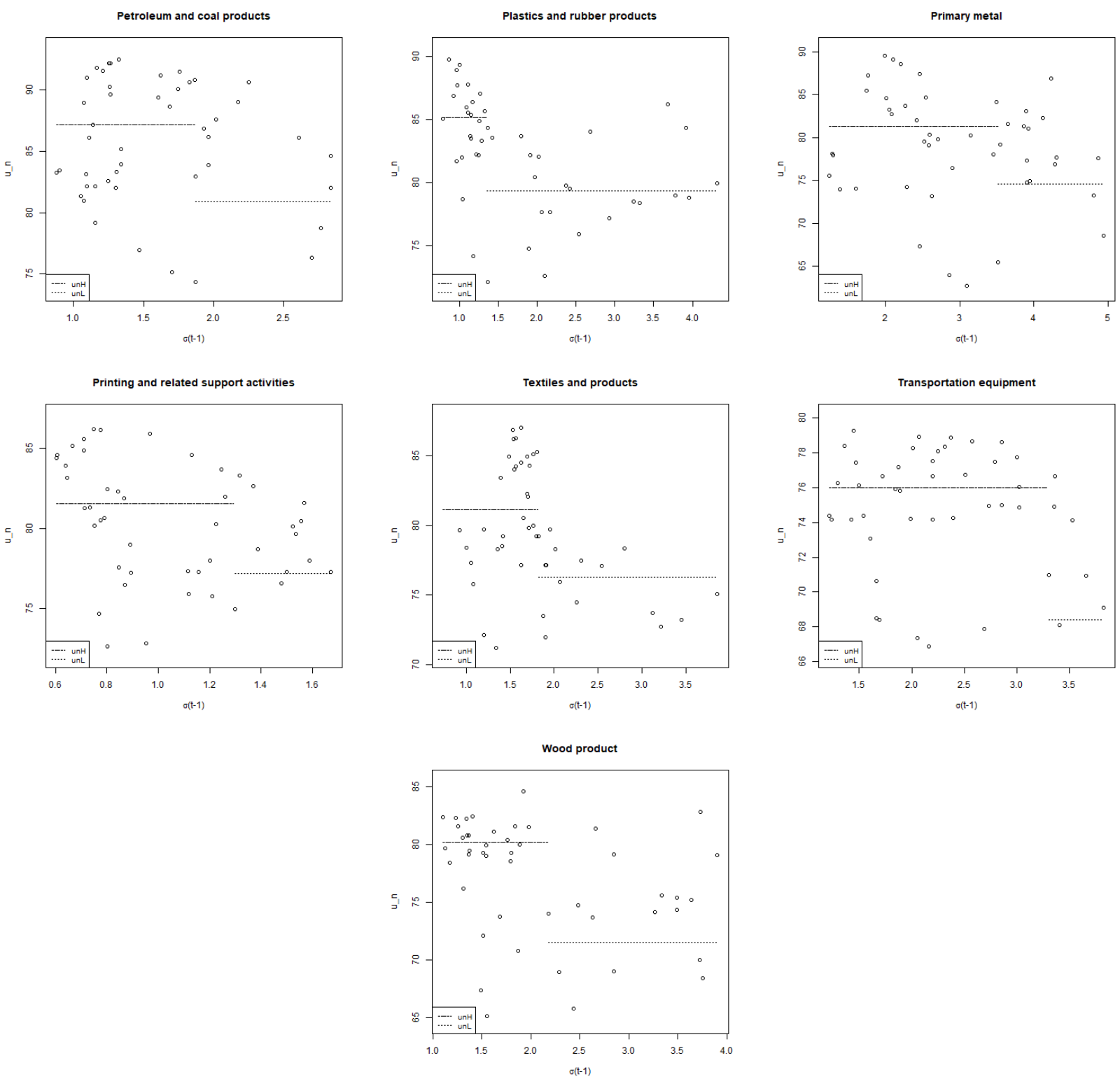

The figures show the scatter plots for the sector-specific $u_{n}$ and $\sigma_{t-1}$. Further, these graphs depicts the upper and lower rate of $u_{n}\left(u_{n H}\right.$ and $\left.u_{n L}\right)$. 


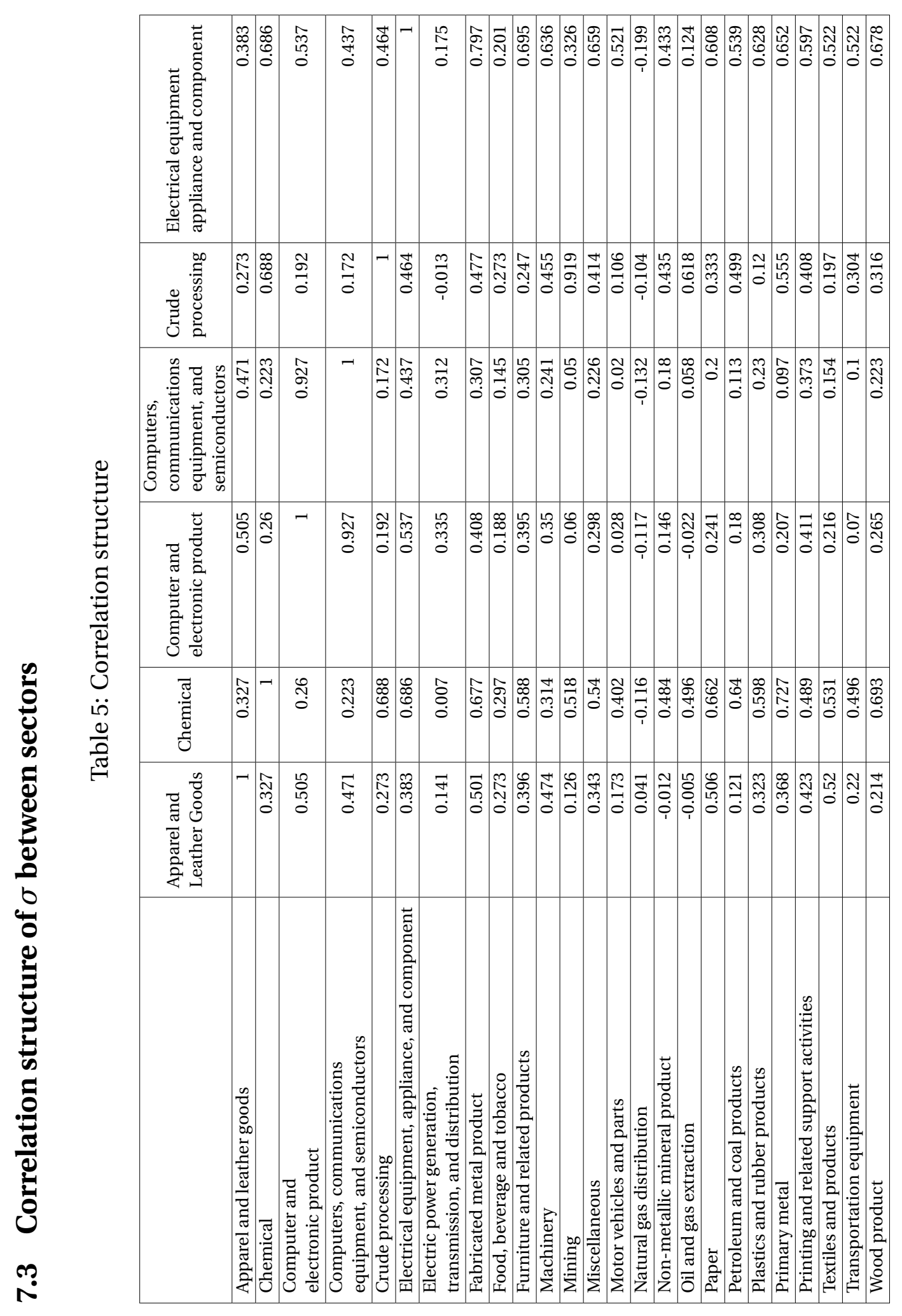




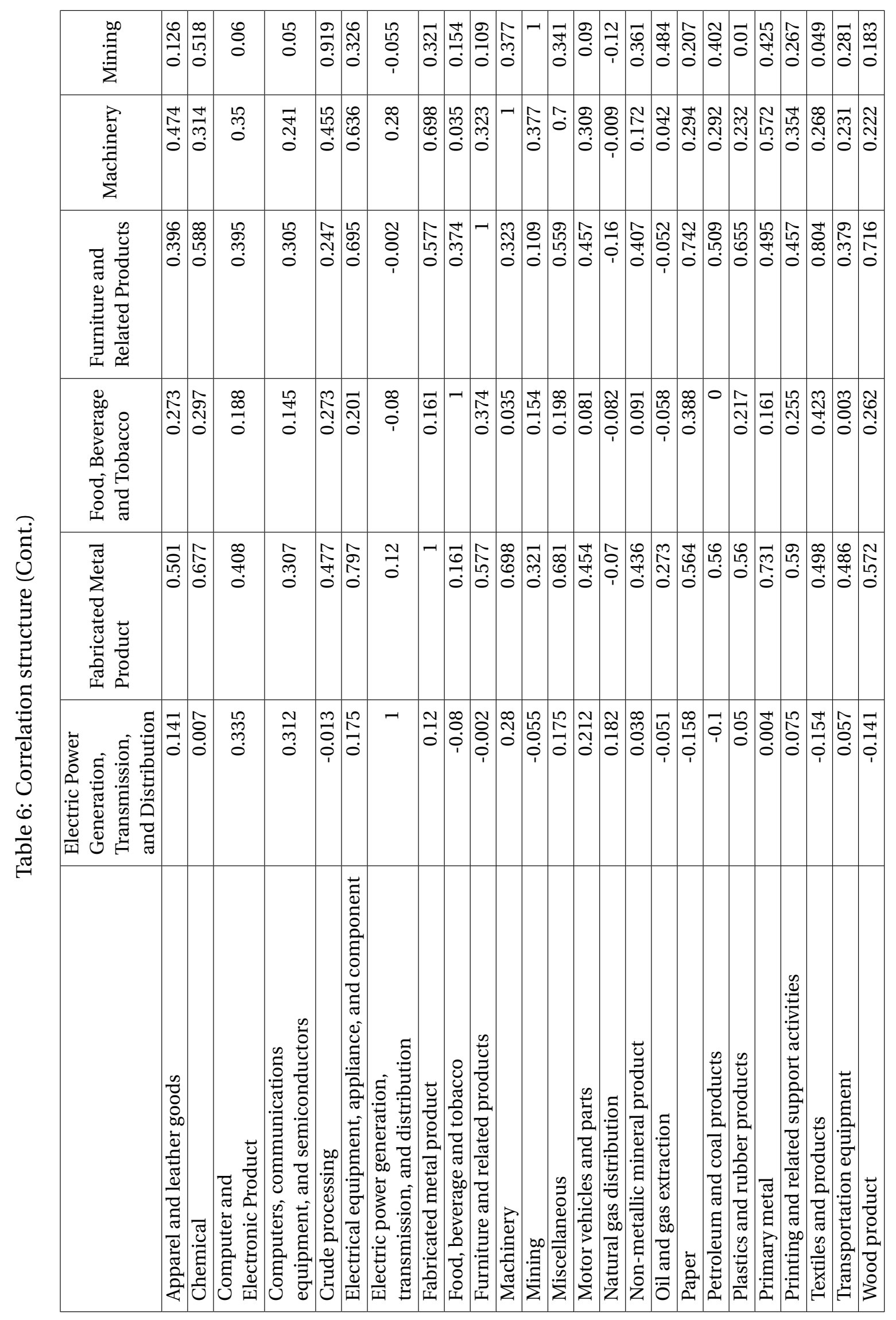




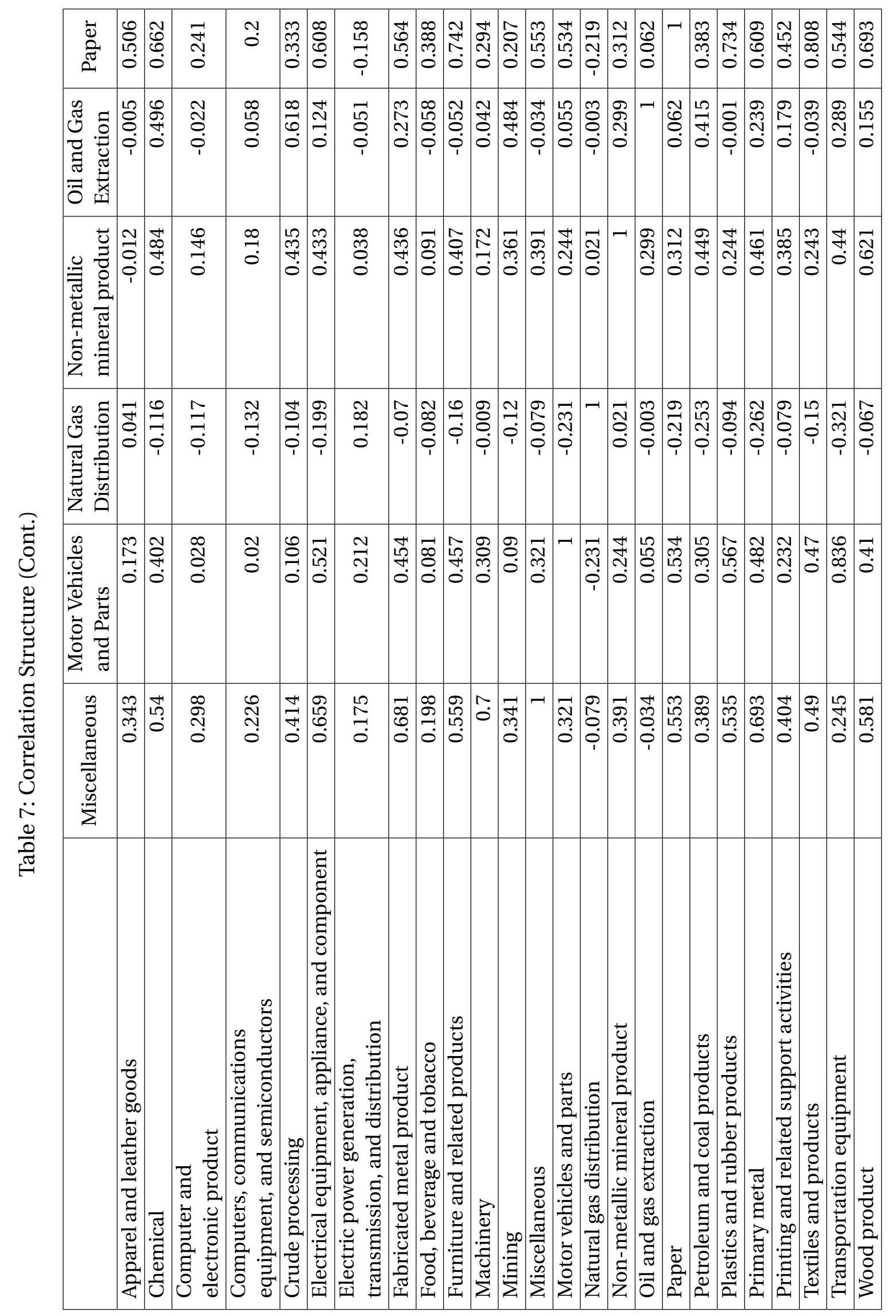




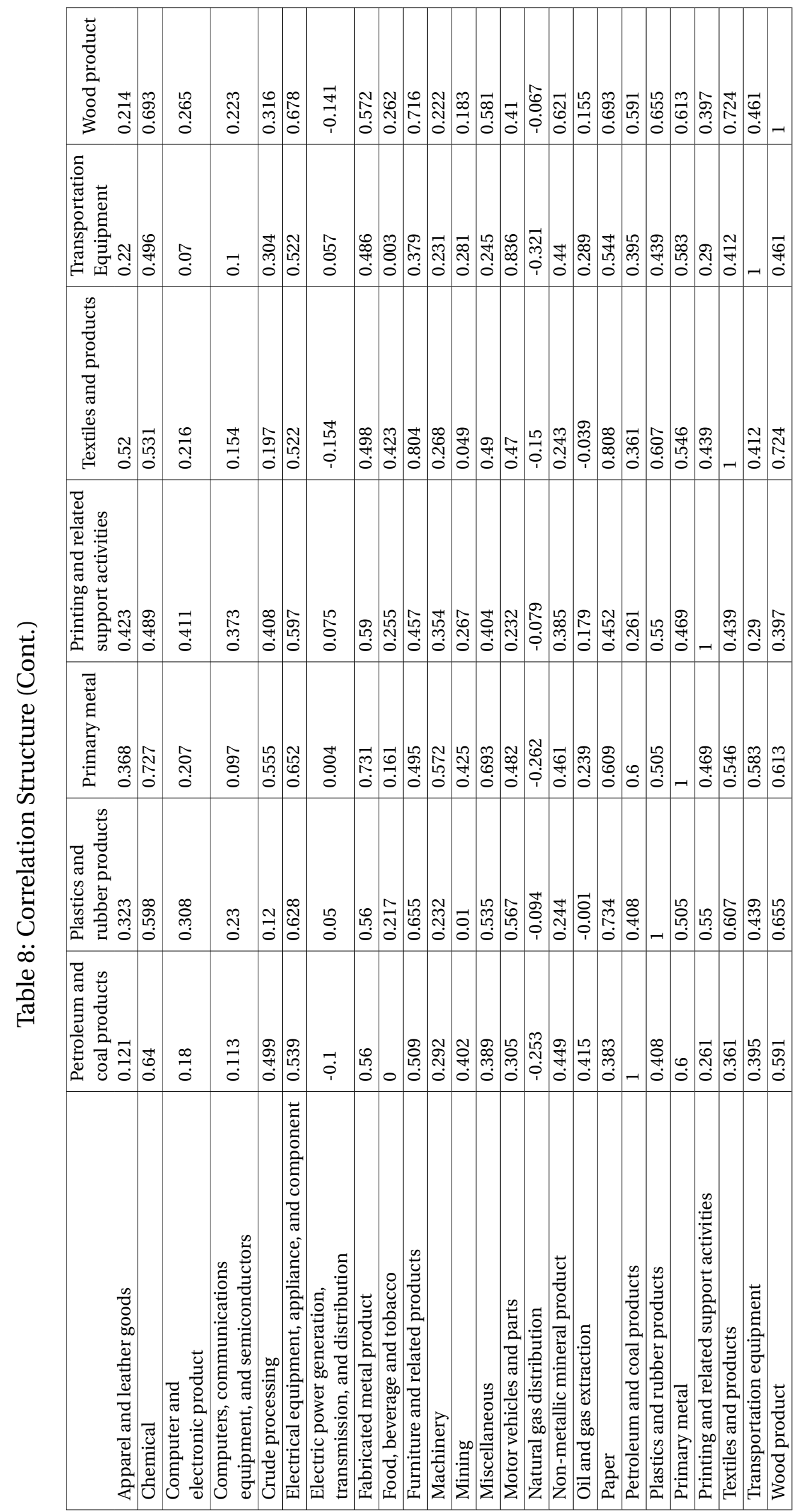




\subsection{Model parameters and calibration}

Table 9 reports the model parameters. Columns 2 and 3 present the parameters used to produce the random draws from the sector-specific log-normal distribution of $\sigma^{j}$. The values are computed for $\sigma$ as the annual standard deviation of the actual capacity utilization (computed for 47 years). The sector-specific empirical distributions of annual $\sigma$ are, in general, best approximated by log-normal distributions. The first and second moments of these distributions ( $\mu$ and $\sigma$-Log-Normal) were calculated by means of Maximum-Likelihood estimation. The draws were further fitted to reflect the cross-correlations between industries, as reported in tables 5,8 The draws from multivariate log-normal distributions were generated with R-Studio and imported into our Netlogo simulations. The relative importance weights (RIW) of the various sectors appear in column 4. These are the mean values of the RIWs for each sector 1990-2007, taken from Setterfield (2019).

The values of $c_{\sigma}^{j}$ are taken from table $2\left(c_{\text {thresh }}\right)$. These were computed using the discrete threshold regression model discussed in section 3.2. The values for those sectors for which we could not find a threshold (Electric power generation, transmission, and distribution; Food, beverage, and tobacco; Natural gas distribution and Oil and gas extraction) were approximated by the average value of the filtered (5-MA) $\sigma, 1972-2018$. Even though the discrete threshold regression model could not detect a sectoral threshold for these industries, the remainder of our empirical analysis (section 3.1) suggests that the hysteresis mechanism is operative in these sectors, justifying our imputation of threshold values for these sectors. The values of $\chi^{L j}$ and $\chi^{U j}$ were calibrated (via indirect calibration (Fagiolo et al. 2007)) so as to approximate the results of the threshold regression models with respect to $u_{n, H}, u_{n, L}$ and the threshold value $c_{\sigma}^{j}\left(c_{t h r e s h}\right)$ of the empirical data (table 2). The results are reported in table 3 .

The parameter $z$ denotes the number of periods required for a firm in any given sector to decide that volatility has decreased sufficiently to merit switching from $u_{n L}$ to $u_{n H}$ (see eq. 12). Specifically, each firm computes the average value of $\sigma$ over the previous $z$ periods $\left(\frac{1}{z} \sum_{l=1}^{z} \sigma_{t-l}^{i, j}\right)$ 
and switches to $u_{n H}$ if the computed average falls below the critical value $c_{\sigma L}^{i, j}$. Similarly, $m$ denotes the number of periods required for a firm in any given sector to decide that volatility has increased sufficiently to merit switching from $u_{n H}$ to $u_{n L}$ (see eq. 11). In this case, a firm that computes the average value of $\sigma$ over the previous $m$ periods $\left(\frac{1}{m} \sum_{l=1}^{m} \sigma_{t-l}^{i, j}\right)$ will switch to $u_{n L}$ if the computed average lies above the critical value $c_{\sigma H}^{i, j}$. The value of $z$ was calculated by observing, in the data for each sector, the average number of periods required for the capacity utilization rate to switch from the lower to the upper normal rate regime in the event that $\sigma$ changes from the high to the low volatility regime. A similar process was used to compute $m$.

Table 9: Calibrated parameters

\begin{tabular}{|c|c|c|c|c|c|c|c|c|}
\hline Sector & $\mu$ (log-normal dist.) & $\sigma$ (log-normal dist.) & $\mu_{R I W}$ & $c_{\sigma}^{j}$ & $\chi^{L j}$ & $\chi^{U j}$ & $z$ & $m$ \\
\hline Apparel and leather goods & 0.344 & 0.517 & 0.0116 & 1.23 & 1.5 & 0.1 & 3 & 3 \\
\hline Chemical & -0.027 & 0.624 & 0.0824 & 1.24 & 0.6 & 0.6 & 3 & 3 \\
\hline Computer and electronic product & 0.103 & 0.692 & 0.0735 & 2.01 & 0.1 & 1.2 & 5 & 3 \\
\hline $\begin{array}{l}\text { Computers, communications equipment, } \\
\text { and semiconductors }\end{array}$ & 0.389 & 0.717 & 0.0498 & 2.57 & 0.1 & 1.5 & 3 & 3 \\
\hline Crude processing & 0.108 & 0.627 & 0.094 & 1.65 & 0.1 & 0.6 & 8 & 4 \\
\hline $\begin{array}{l}\text { Electrical equipment, appliance, } \\
\text { and component }\end{array}$ & 0.265 & 0.649 & 0.0187 & 1.45 & 0.6 & 1.2 & 0 & 2 \\
\hline $\begin{array}{l}\text { Electric power generation, transmission, } \\
\text { and distribution }\end{array}$ & 0.446 & 0.291 & 0.0655 & 1.74 & 0.3 & 0.6 & 3 & 3 \\
\hline Fabricated metal product & 0.032 & 0.669 & 0.045 & 2.16 & 0.3 & 1.8 & 11 & 0 \\
\hline Food, beverage and tobacco & -0.397 & 0.423 & 0.0842 & 0.81 & 0.3 & 0.6 & 3 & 3 \\
\hline Furniture and related products & 0.336 & 0.573 & 0.0127 & 1.59 & 0.9 & 0.1 & 5 & 2 \\
\hline Machinery & 0.528 & 0.548 & 0.0452 & 2.66 & 0.1 & 1.2 & 8 & 2 \\
\hline Mining & 0.244 & 0.593 & 0.061 & 1.53 & 0.6 & 0.1 & 6 & 4 \\
\hline Miscellaneous & 0.452 & 0.646 & 0.0229 & 1.12 & 1.2 & 0.3 & 3 & 0 \\
\hline Motor vehicles and parts & 1.101 & 0.55 & 0.0508 & 4.31 & 0.6 & 1.8 & 3 & 2 \\
\hline Natural gas distribution & 1.213 & 0.361 & 0.0105 & 3.64 & 1.8 & 1.5 & 3 & 1 \\
\hline Non-metallic mineral mining and quarrying & 0.892 & 0.375 & 0.0174 & 3.13 & 0.1 & 1.2 & 6 & 3 \\
\hline Oil and gas extraction & -0.037 & 0.553 & 0.0393 & 1.08 & 1.8 & 0.9 & 5 & 3 \\
\hline Paper & 0.214 & 0.555 & 0.0249 & 1.23 & 1.2 & 0.6 & 3 & 2 \\
\hline Petroleum and coal products & 0.325 & 0.488 & 0.0164 & 1.87 & 0.1 & 0.6 & 10 & 4 \\
\hline Plastics and rubber products & 0.328 & 0.679 & 0.028 & 1.36 & 1.8 & 0.1 & 4 & 2 \\
\hline Primary metal & 0.877 & 0.58 & 0.022 & 3.52 & 0.1 & 1.8 & 4 & 6 \\
\hline Printing and related support activities & -0.098 & 0.501 & 0.0198 & 1.30 & 0.1 & 0.6 & 6 & 3 \\
\hline Textiles and products & 0.356 & 0.624 & 0.012 & 1.82 & 0.9 & 1.2 & 3 & 3 \\
\hline Transportation equipment & 0.635 & 0.601 & 0.0806 & 3.30 & 0.1 & 1.8 & 1 & 0 \\
\hline Wood product & 0.507 & 0.613 & 0.0118 & 2.18 & 1.2 & 0.6 & 3 & 5 \\
\hline
\end{tabular}

Source: Federal Reserve Bank of St. Louis (FRED) and the US, and own calculation. 


\subsection{Robustness check: discrete threshold regression model with time trend}

In order to further examine the presence of hysteresis in the normal rate of utilization, we estimate the discrete threshold regression model using our filtered (5-MA) data, but without removing the linear trend. In other words, the data for the regressions that follow is filtered but not detrended. This revised discrete threshold regression model serves as a robustness check for the results reported in table 2, which are derived from estimates of a discrete threshold regression model using the filtered (5-MA) and detrended annual average rate of capacity utilization (i.e. $u_{n}$ ). The discrete threshold regression model estimated here involves two linear regressions with the same marginal effect in the time trend $t$ but with two different intercepts, separated at a the threshold value of $\sigma_{t-1}$ as shown in equations (20) and 21):

$$
\begin{array}{ccc}
u_{n t}=C_{1}+\beta * t+\epsilon_{t} & \text { if } & 0<\sigma_{t-1}<\sigma_{\text {thresh }} \\
u_{n t}=C_{2}+\beta * t+\epsilon_{t} & \text { if } & \sigma_{\text {thresh }}<\sigma_{t-1}<\infty
\end{array}
$$

In this revised model, the normal capacity utilization rate is the dependent variable, the year $(t)$ is the independent non-threshold variable and $\sigma_{t-1}$ is the threshold variable.

Table 10 presents the results, which support those found in table 2. Table 2 shows that there

exists a threshold value of $\sigma_{t-1}$ in nearly every sector. Thus, the intercept value of $u_{n}$, the sectoral normal rate of capacity utilization, drops if the threshold value for the (lagged) value of $\sigma$ is exceeded. 


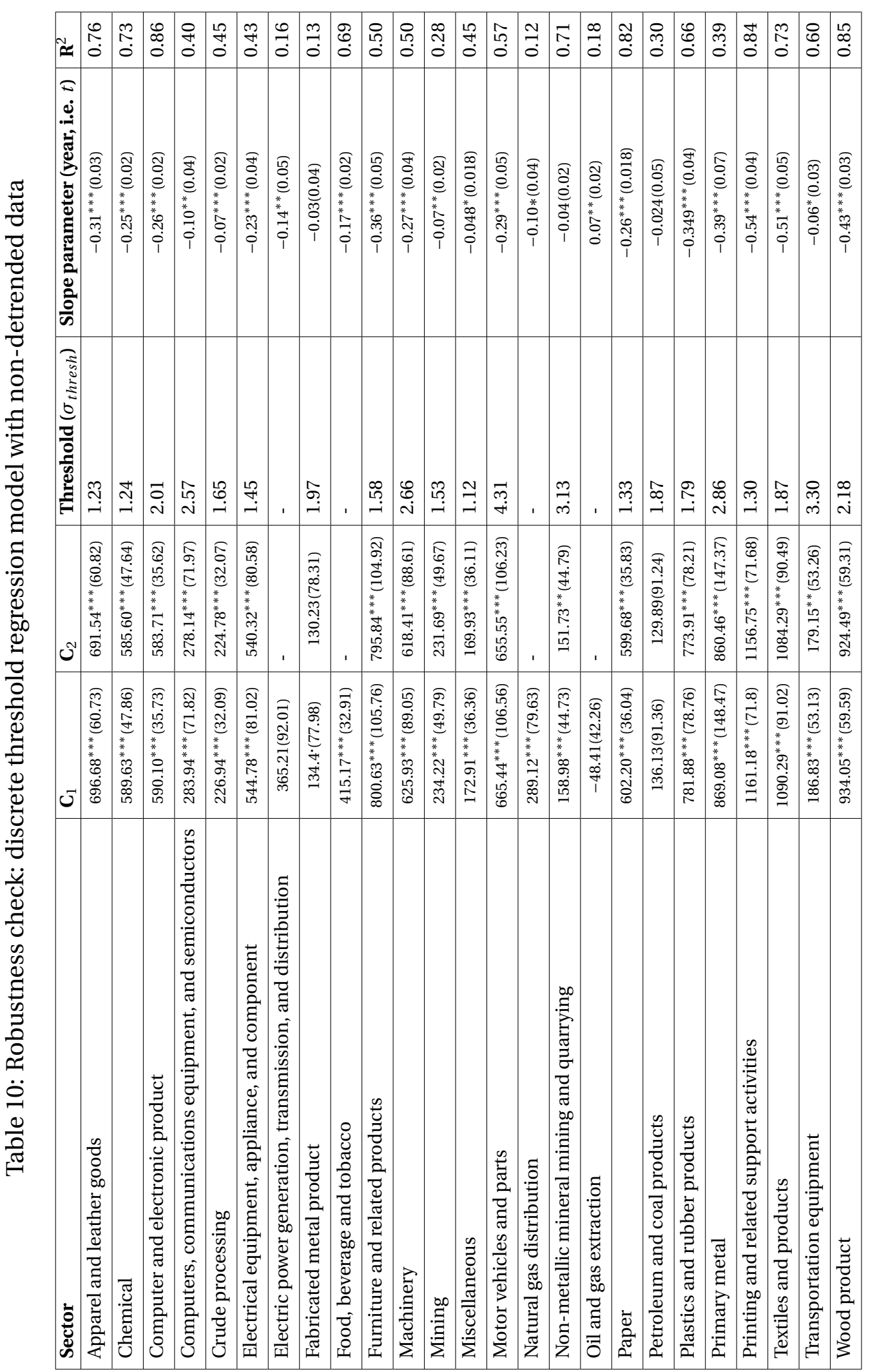

‡

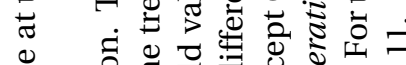

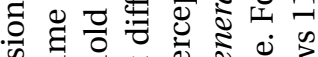

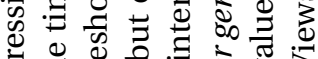

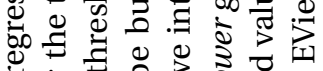

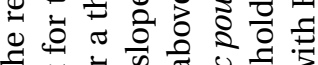
$\Rightarrow$ क 응 웡 노에 就

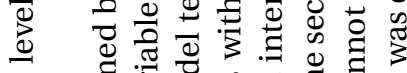
을

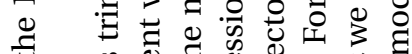

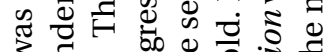
उ

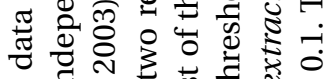

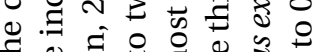

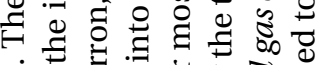
ง.

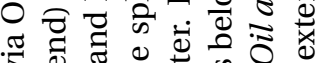
50

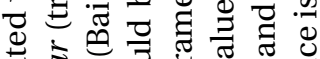

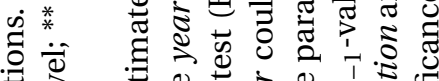

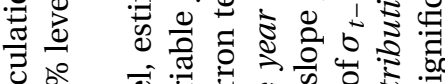

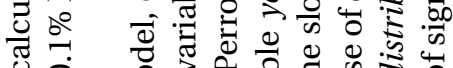
उ. క

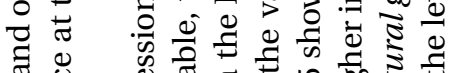

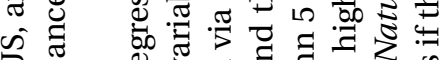
Q 豆

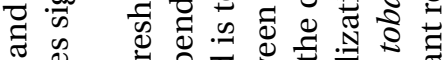

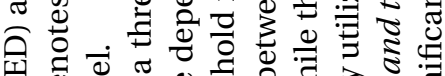
牙讨

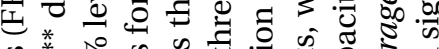
क 0 讨 फे

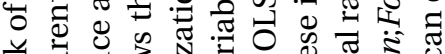

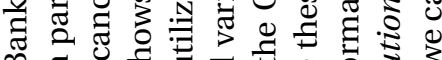

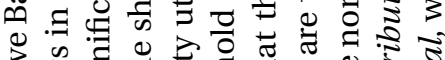

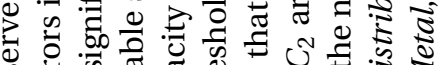
के के ज्ञ

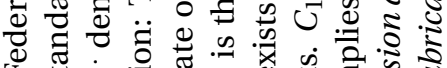
造 نू

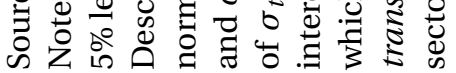




\subsection{Robustness checks for sectoral (mesoeconomic) indicators}

In order to analyze the sensitivity of the model to deviations in the baseline parameter setting with respect to the results of the sectoral threshold regression models (table 3 in section 4.2 , we simulate the model of section 4.1 with small changes in the parameterization. As far as possible, we increase and decrease the baseline values of $\chi^{L_{j}}$ and $\chi^{U_{j}}$ by \pm 0.3 units and run each combination for 100 Monte Carlo simulations (i.e. 100 random seeds) and 400 periods. Thus, we run (at maximum) 400 simulations. We then compute the threshold regression model $\left(C_{1}, C_{2}\right.$ and threshold $-\sigma_{t-1}$ ) for each of these additional runs over 350 periods (400 periods minus 50 periods burn-in phase). Further, we compute the average $u_{n}$ of each run. We analyze whether the samples of the regression results (4 combinations and 100 random seeds per combination (at maximum)) differ from sample of results of the simulations of the calibrated model (100 random seeds as in table 3). We apply a two-sample Wilcoxon-test for each indicator $\left(C_{1}, C_{2}\right.$, threshold- $\sigma_{t-1}$ and average $u_{n}$ ). Table 11 contains the results. In short, for the majority of the sectors, small deviations from the calibration do not strongly affect the model output. In very few cases, the Wilcoxon-test rejects the null-hypothesis that the calibrated model produces significantly different values for $C_{1}, C_{2}$, threshold- $\sigma_{t-1}$ and the average of $u_{n}$ when compared to the model with small changes in the parameterization. Thus, the model (i.e., the model output with respect to the threshold regressions) is reasonably robust with respect to small changes in parameter values. Therefore, small deviations in the parameterization do not reduce the model's ability to produce data that is reasonably close to the actual sectoral data. 


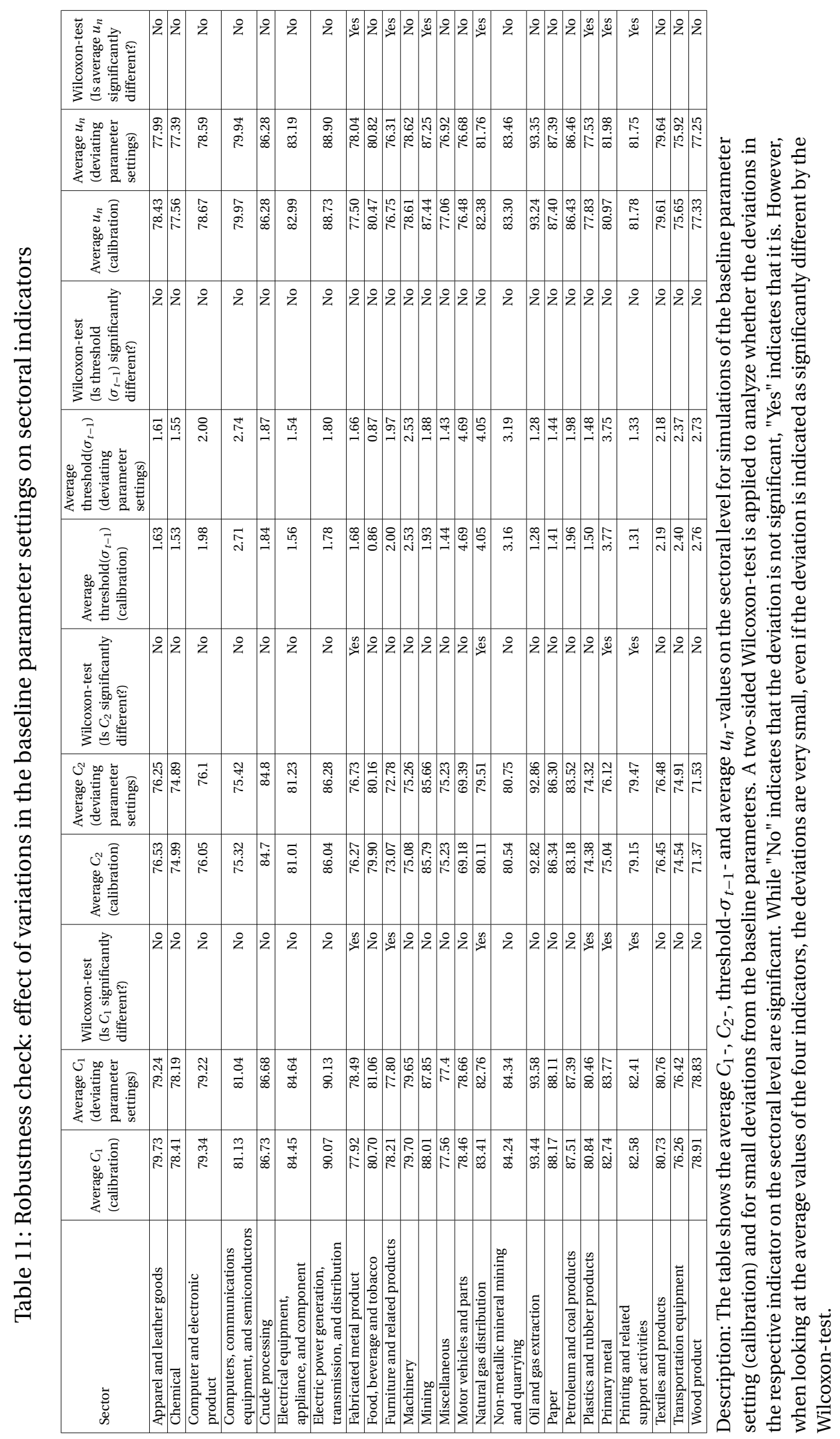




\subsection{Robustness checks for macroeconomic indicators}

Apart from analyzing the sensitivity of the model to baseline parameter variations with respect to sectoral indicators, we analyze the sensitivity also with respect to changes in macroeconomic data, i.e., table 4 in section 4.3 . Similar to the robustness checks presented in the previous section, we simulate the model of section 4.3 with small changes in the parameterization. We increase and decrease the baseline values of $\chi^{L_{j}}$ and $\chi^{U_{j}}$ by a random draw from a uniform distribution $(U[-0.1,0.1])$. We took 3,000 draws for each sector. We then run each of the 3,000 combinations and insert the empirical fluctuations of sectoral $\sigma$, similar to the simulation studies in section 4.3. Each run is simulated for 300 periods. For each of the 3,000 runs, we compute the average, the maximum, the minimum and the standard deviation of $u_{n}$ at the macroeconomic level over 250 periods (300 periods minus 50 periods burn-in phase). We compare the distributions of the indicators with the same macroeconomic indicators for 100 runs of the model in the baseline parameterization (see table 4 in section 4.3). The boxplots in figures $17-20$, contain the distributions of the respective variables for the baseline parameter specifications (indicated by 1 ) and alternative parameter settings (indicated by 0 ). For the majority of variables small deviations from the (ideal) calibration do not strongly affect the model output. Thus, there is again evidence that the model is robust with respect to parametric changes, and that such changes do not reduce the model's ability to produce macroeconomic data that is close to the data actually observed at the macroeconomic level. 
Figure 17: Robustness check: effect of variations in the baseline parameter settings on macroeconomic indicators - distribution of average $u_{n}$ (calibrated vs. alternative settings)

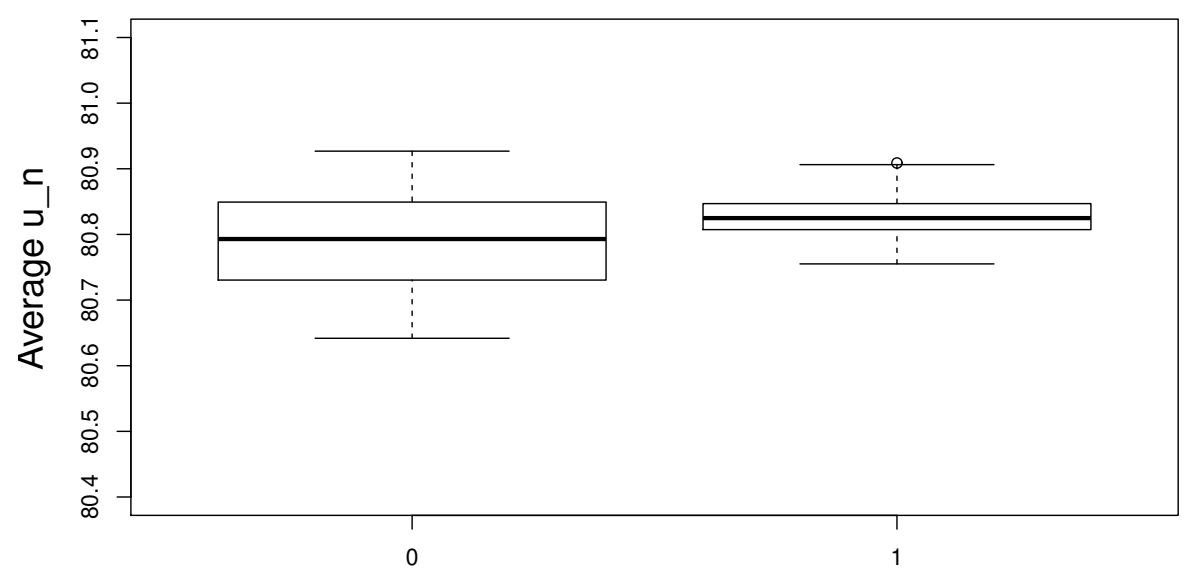

Alternative settings (0) vs. calibrated parameter (1)

Description: Figure shows the distribution of the average macroeconomic $u_{n}$ for the baseline parameterization (100 random seeds) on the right and for 3,000 alternative parameter combinations (deviating from the baseline parameterization) on the left. We trimmed the values of the left boxplot by $10 \%$. 
Figure 18: Robustness check: effect of variations in the baseline parameter settings on macroeconomic indicators - distribution of maximum $u_{n}$ (calibrated vs. alternative settings)

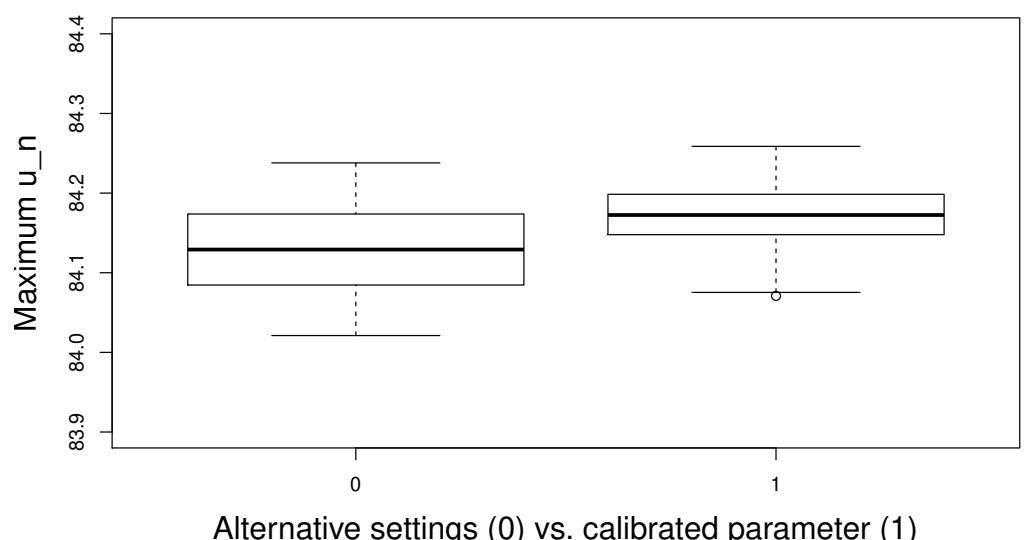

Description: Figure shows the distribution of the maximum macroeconomic $u_{n}$ for the baseline parameterization (100 random seeds) on the right and for 3,000 alternative parameter combinations (deviating from the baseline parameterization) on the left. We trimmed the values of the left boxplot by $10 \%$.

Figure 19: Robustness check: effect of variations in the baseline parameter settings on macroeconomic indicators - distribution of minimum $u_{n}$ (calibrated vs. alternative settings)

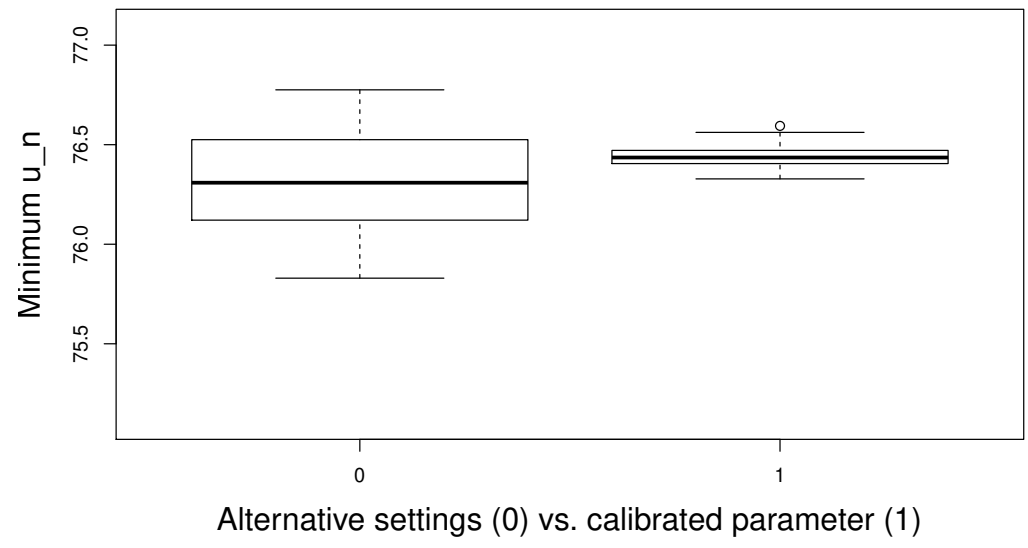

Description: Figure shows the distribution of the minimum macroeconomic $u_{n}$ for the baseline parameterization (100 random seeds) on the right and for 3,000 alternative parameter combinations (deviating from the baseline parameterization) on the left. We trimmed the values of the left boxplot by $10 \%$. 
Figure 20: Robustness check: effect of variations in the baseline parameter settings on macroeconomic indicators - distribution of standard deviations of $u_{n}$ (calibrated vs. alternative settings)

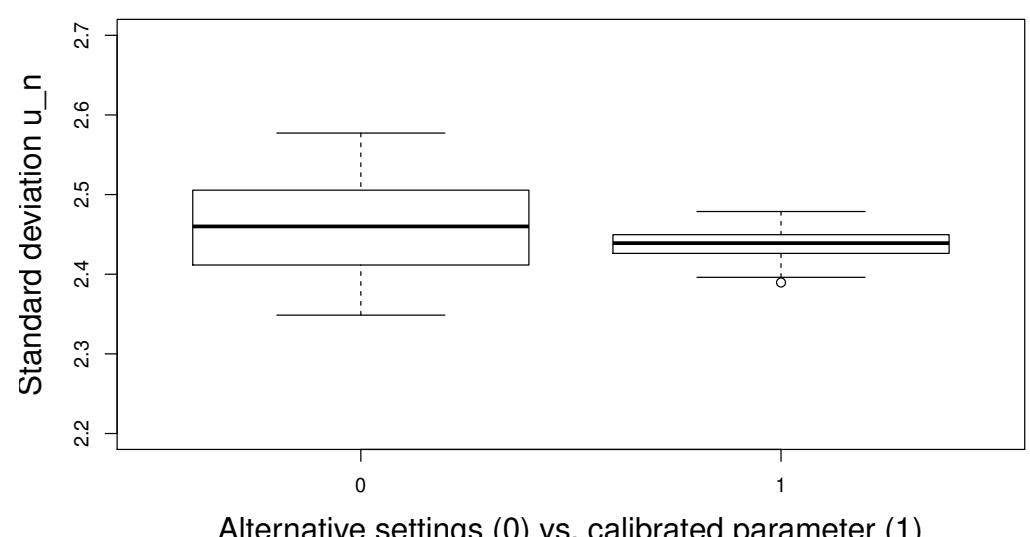

Description: Figure shows the distribution of the standard deviation of the macroeconomic $u_{n}$ for the baseline parameterization (100 random seeds) on the right and for 3,000 alternative parameter combinations (deviating from the baseline parameterization) on the left. We trimmed the values of the left boxplot by $10 \%$. 